OPEN ACCESS

Edited by:

Oleh Khalimonchuk,

University of Nebraska-Lincoln,

United States

Reviewed by:

John Hancock,

University of the West of England,

United Kingdom

Frank Thévenod

Witten/Herdecke University, Germany

*Correspondence:

Dacheng Liang

dachengliang@gmail.com

Specialty section:

This article was submitted to

Signaling,

a section of the journal

Frontiers in Cell and Developmental

Biology

Received: 20 November 2017

Accepted: 18 January 2018

Published: 06 February 2018

Citation:

Liang D (2018) A Salutary Role of

Reactive Oxygen Species in

Intercellular Tunnel-Mediated

Communication.

Front. Cell Dev. Biol. 6:2.

doi: 10.3389/fcell.2018.00002

\section{A Salutary Role of Reactive Oxygen Species in Intercellular Tunnel-Mediated Communication}

\author{
Dacheng Liang ${ }^{1,2 *}$ \\ ${ }^{1}$ Hubei Collaborative Innovation Center for Grain Industry, School of Agriculture, Yangtze University, Jingzhou, China, \\ ${ }^{2}$ Engineering Research Center of Ecology and Agricultural Use of Wetland, Ministry of Education, Yangtze University, \\ Jingzhou, China
}

The reactive oxygen species, generally labeled toxic due to high reactivity without target specificity, are gradually uncovered as signaling molecules involved in a myriad of biological processes. But one important feature of ROS roles in macromolecule movement has not caught attention until recent studies with technique advance and design elegance have shed lights on ROS signaling for intercellular and interorganelle communication. This review begins with the discussions of genetic and chemical studies on the regulation of symplastic dye movement through intercellular tunnels in plants (plasmodesmata), and focuses on the ROS regulatory mechanisms concerning macromolecule movement including small RNA-mediated gene silencing movement and protein shuttling between cells. Given the premise that intercellular tunnels (bridges) in mammalian cells are the key physical structures to sustain intercellular communication, movement of macromolecules and signals is efficiently facilitated by ROS-induced membrane protrusions formation, which is analogously applied to the interorganelle communication in plant cells. Although ROS regulatory differences between plant and mammalian cells exist, the basis for ROS-triggered conduit formation underlies a unifying conservative theme in multicellular organisms. These mechanisms may represent the evolutionary advances that have enabled multicellularity to gain the ability to generate and utilize ROS to govern material exchanges between individual cells in oxygenated environment.

Keywords: ROS, intercellular movement, interorganelle transport, membrane protrusions, plasmodesmata, tunneling nanotubes (TNTs), macromolecule movement, multicellularization

\section{INTRODUCTION}

Various cellular metabolic processes, ranging from energy capture and storage in chloroplast, long chain carbon metabolism in peroxisome, to energy generation in mitochondria, all under normal physiological condition, accompany with the generation of one type of products: the reactive oxygen species (ROS) (Halliwell and Gutteridge, 1989; Scandalios, 1997; Davies, 2000; Apel and Hirt, 2004). The mechanisms of ROS formation during these metabolic processes abound (Hinshaw et al., 1986; Al-Mohanna and Hallett, 1987; Quinn et al., 1989; Apel and Hirt, 2004; Asada, 2006; Pospísil, 2009). The most well-known is oxygen's stepwise reduction principle in which oxygen molecule in its ground state can only accept one electron at a time to be reduced into superoxide 
anion $\left(\mathrm{O}_{2}^{\bullet}-\right)$, then further into hydrogen peroxide $\left(\mathrm{H}_{2} \mathrm{O}_{2}\right)$, hydroxyl radical $(\cdot \mathrm{OH})$ and water, or excited into singlet oxygen $\left({ }^{1} \mathrm{O}_{2}\right)$ via energy transfer (Klotz, 2002; Turrens, 2003; Apel and Hirt, 2004; Sharma et al., 2012). These ROS intermediates energetically react with biomolecules in a non-selective way and perhaps prompt further production of other destructive radicals, thus posing great threats to cellular integrity and viability. Coping with aerobic metabolism, aerobic life has evolved antiROS system including non-enzymatic antioxidant and ROSscavenging enzymes to ameliorate the toxic effects imposed by ROS (Raghu et al., 1986; Abid et al., 2000). Actually, the tug of war between ROS and antioxidant system has been on play since evolution of early life living in less oxic environment (Moldovan et al., 2000; Harfouche et al., 2005); for instance, the advent of enzymatic antioxidants such as superoxide dismutase (SOD), catalase and peroxiredoxin in organisms appearing on Earth around 4.1-3.5 billion years ago-around 1 billion years earlier than the great oxidation event, which highlights the paramount role of anti-ROS system in life evolution on Earth. This can be further seen from photosynthetic organisms that are equipped with a host of delicate, sophisticated non-enzymatic antioxidants as diverse as vitamins (e.g., Vitamin C, Vitamin E), amino acids (e.g., proline), peptide (e.g., GSH), carotenoids (e.g., $\beta$ carotene, lycopene, lutein), flavonoids (e.g., quercetin, catechin), and hormone (e.g., melatonin) (Sundaresan et al., 1995; Choi et al., 2005; Connor et al., 2007; Schröder et al., 2007; Lee et al., 2009).

Existence of such colossal antioxidants in aerobic life may easily lead to an illusion that ROS is flat-out toxic and doing nothing good. On the contrary, the past several decades have seen the growing evidence of ROS as important signaling molecules. The first recognized biological value of ROS in plants came from their integration into defense system against pathogen. Earlier experiments found hydrogen peroxide served as important signal to trigger local cell death and to induce antioxidant activation in adjacent cells (Daszkowska-Golec and Szarejko, 2013) and systemic acquired resistance (Shimazaki et al., 2007; Song et al., 2014). Derived from oxidative burst, one of the earliest events following pathogen challenge, $\mathrm{H}_{2} \mathrm{O}_{2}$ can rapidly-within several minutes-accumulate to a considerable level, e.g., magnitude of millimolar concentration in soybean cells (Apostol et al., 1989; Stahl and Simon, 2013). An analogous scenario is found in a confined organelle, or phagosome of immune cells, where ROS, produced at the millimolar quantities of $\mathrm{H}_{2} \mathrm{O}_{2}$, are used to kill intruding pathogens (Babior et al., 1973; Lucas and Lee, 2004; Adamec, 2006, 2007; Roelfsema and Hedrich, 2010). Later more than a decade studies revealed that the intentional production of ROS was largely driven by the activity of NOX complex (NADPH oxidase) (Royer-Pokora et al., 1986; Teahan et al., 1987; Babior, 2004; Bedard and Krause, 2007) or its plant counterpart, RBOHNADPH oxidase (Torres et al., 2002; Sagi and Fluhr, 2006; Suzuki et al., 2011). Not surprisingly, other enzymes characterized from both animals and plants, such as peroxidase (Klebanoff, 1970; Bindschedler et al., 2006; Choi et al., 2007; O'Brien et al., 2012; Kimura et al., 2014), oxidoreductase (e.g., xanthine oxidase, Hille and Nishino, 1995; Harrison, 2002; Zarepour et al., 2010; Ma et al., 2016), oxalate oxidase (Requena and Bornemann,
1999), and oxygenase (e.g., cyclooxygenase and lipoxygenase) also contribute to the internal ROS production.

In addition to the involvement in biotic defense, these ROS-generating machineries together with antioxidants act as essential modulators of redox signaling pathways capable of effecting changes in a plethora of biological processes including, not limited to, abiotic stress, cell growth and programmed cell death, cell proliferation, and cell differentiation. For more excellent reviews, reader is referred to those by Holmström and Finkel (2014), Río and Puppo (2009), Rhee (2006), Finkel (2011), Farmer and Mueller (2013), Foyer and Noctor (2005), Mittler et al. (2011), Ray et al. (2012), Baxter et al. (2014), and Sewelam et al. (2016). Nevertheless, a latent aspect in the repertoire of ROS function has not yet brought into discussion until recently; their emerging role in modulating cell-to-cell information flow through plasmodesmata (PD) in plant and their inductive capability to produce membrane protrusions between mammalian cells, as well as among organelles in plant cells. Thanks to some new approaches adopted to uncover this longneglected regulatory mechanism, we can get the glimpse of how ROS, particularly $\mathrm{H}_{2} \mathrm{O}_{2}$, are generated and incorporated into intercellular bridge-mediated communication by promoting membrane protrusions formation (in both animal and plant cells) and cell wall remodeling (in plant cells). This review is focused on the genetic control of intercellular movement of various molecules including symplastic dye, small RNA, and proteins, and outlines the underlying mechanisms that are shared across plant and animal kingdoms.

\section{DYEING SYMPLASTIC MOVEMENT-ROLE FOR ROS}

Intercellular transport in plants is believed to be one of the most fundamental processes for which PD embedded in the cell wall but connecting cytoplasm of neighbor cells is essential to enable the cell-cell symplastic exchange. The PD-mediated intercellular communication can be observed through symplastic dye loading experiment, e.g., CFDA-coupling (Wang and Fisher, 1994), Lucifer Yellow CH injection (van Kesteren et al., 1988), and HPTS loading experiment (Gisel et al., 1999). Copious data accumulated from studies on symplastic tracer loading in model plant Arabidopsis, as well as in monocots and woody plants, provides indicative insights into the recognition of relative disconnection from surrounding tissues in some types of cell clusters/tissues, or namely the symplastic domain (van der Schoot and van Bel, 1990; Botha and van Bel, 1992; Rinne and van der Schoot, 1998; Ding et al., 2003) in which the cell-to-cell connection is highly united into a continuity, but temperally and spacially cut-off from other cells/tissues. This phenomenon posed an immediate question as how the symplastic domains are formed and how they are regulated during plant development.

Genetic screens from the embryo-defective collection, which was predicated on the premise that defective cellto-cell transport would result in the embryo abnormality or growth arrest, recovered mutants showing increased plasmodesmatal conductance of symplastic dye, e.g., the 
10-kD F-dextran (Kim I. et al., 2002; Kobayashi et al., 2007; Burch-Smith and Zambryski, 2010), or decreased movement of small dye, e.g., HPTS (Xu et al., 2012), at different stages of embryo development, further adding weight to the idea that the symplastic domain is dynamically regulated (Gisel et al., 1999; Ding et al., 2003). However, subsequent outcome from map-based cloning of causal mutation in these mutant lines attested to a diversified genetic pathway in which the genetic component seems not directly link to each other, either spacially or chemically. For instance, both ISE1 and ISE2 (INCREASED SIZE EXCLUSION LIMIT OF PLASMODESMATA 1 or 2) gene encode two different RNA helicases that are involved in the very basic aspect of RNA metabolism ranging from RNA transcription, splicing to degradation, and that are localized to mitochondria and chloroplast respectively, whereas DSE1 (decreased size exclusion limit 1) gene encodes a WD-repeat protein that is distributed in both cytoplasm and nucleus. Although these genes controlling the cell-to-cell movement of symplastic tracer appear to have no apparent intrinsic coherence in light of genetic and/or biochemical pathways or even the spacial occurrence relating to PD, TEM dissection has shown these mutants have altered architecture of PD; with increased frequency of twinned and branched $\mathrm{PD}$ in increased tracer movement mutant or decreased frequency of twinned and branched PD in decreased tracer movement mutant.

These results have clearly shown PD-mediated transport indicated by symplastic tracer is paramount, and as such the mutants are often displaying severe phenotypic abnormalities as diverse as retarded growth, altered flowering time, dysfunctional reproductive organs, and even embryo lethal from strong mutant allele. Concomitant to the abnormal growth of mutant lines, the ROS level is apparently higher in the ise1 mutant as opposed to the wild type plant, which might be explained as a result of developmental disruption of mitochondria or chloroplast (Burch-Smith et al., 2011). Though ROS measurement is not available to $d s e 1$ or ise 2 mutant, anthocyanin, known as stressinducible phytochemical, is accumulated in the embryo of $d s e 2$ mutant and another allele tan mutant (Xu et al., 2012), and cotyledon of ise 2 mutant as well (Kobayashi et al., 2007), tentatively suggesting that PD-mediated transport might be subject to ROS-related regulatory mechanisms.

Experiments with microinjection showed sodium azide, an agent known to inhibit electron transport in mitochondria complex IV (Petersen, 1977; Yoshikawa et al., 1998), thus leading to ROS augmentation in mammalian cells (Duranteau et al., 1998) and also mitochondrial oxidation in Arabidopsis (Schwarzländer et al., 2009), can enlarge PD pore and enhance the cell-to-cell movement of various dyes (Tucker, 1993). Moreover, the size exclusion limit (SEL) of cortical PD in wheat roots under oxidative stress induced by azide can be increased from $<1 \mathrm{KD}$ to between 5 and $10 \mathrm{kD}$ (Cleland et al., 1994). Astonishingly, this oxidative effect was further applied to breaking down the epidermis-trichome symplastic boundary by increasing SEL in tobacco leaf (Figure 1) (Christensen et al., 2009).

Genetic studies on PD-mediated tracer movement have provided qualitative perspective on cell-cell transport and lent much credence to the test of mathematically modeled permeability. Rutschow et al. (2011) quantified the intercellular permeability of Arabidopsis root meristematic regions by applying the diffusion model to CF bleaching experiment with confocal microscope, and generated a new measurement of PD conductivity, which is nearly an order of magnitude larger than the reported with dye microinjection (Goodwin et al., 1990) (Table 1). Nevertheless, this value discrepancy may lie with the responsiveness of $\mathrm{PD}$ when subjected to the perturbation of handling or environmental stimuli, or the variation of $\mathrm{PD}$ components and structure in different tissues/organs (Radford and White, 2001; Roberts and Oparka, 2003). The validity of this model was further corroborated in two Arabidopsis lines in which the PD-mediated transport is in defect shown before. With this confirmation, the authors made a straightforward test on the role of $\mathrm{H}_{2} \mathrm{O}_{2}$ in intercellular transport that was contrarily demonstrated to be in association with PD conductance in two ROS-elevated mutants: ise1 mutant with increased transport (Stonebloom et al., 2009), but gat1 with decreased transport (Benitez-Alfonso et al., 2009). At relative low concentration of $0.6 \mathrm{mM}, \mathrm{H}_{2} \mathrm{O}_{2}$ can double the $\mathrm{PD}$ permeability, but the opposite effect was observed when plants were exposed to higher concentration, say, $6 \mathrm{mM}$ (Rutschow et al., 2011), alluding that the extent to which the inner ROS accumulated in these mutants (Benitez-Alfonso et al., 2009; Stonebloom et al., 2009), or alternatively in which subcellular organs (Stonebloom et al., 2012), may explain the contradictory repercussions observed in two independent genetic studies. Further studies would aim at defining the boundary of $\mathrm{H}_{2} \mathrm{O}_{2}$ concentration and exploring the cause of adverse effect when plants are exposed to $\mathrm{H}_{2} \mathrm{O}_{2}$.

\section{MOVEMENT OF SMALL RNA-MEDIATED POST-TRANSCRIPTIONAL GENE SILENCING IS CONTROLLED BY HYDROGEN PEROXIDE}

RNA silencing is a conserved defense system against foreign nucleic acid species across a wide range of organisms. Interestingly, this process involving small RNA in size of 21-24 nt is not contained in situ but rather elicits a non-cell-autonomous transmission - in a mode of either short distance movement or of long-distance movement, or both (Kalantidis et al., 2008; Liang et al., 2011; Melnyk et al., 2011). One crucial question concerning the short/long-distance mobile silencing is how the movement of silencing signal is subject to intercellular traffic control.

In C. elegans, intercellular transport of silencing signals depends on the activity of a double stranded RNA (dsRNA) transporter, or SID-1 which enables transport of the length of $50 \mathrm{bp}$ up to $500 \mathrm{bp}$ dsRNAs (Winston et al., 2002). It seems no counterpart of SID-1 in plants is responsible for the silencing movement. Thus, what factors or mechanisms in plants are employed to render silencing dissemination has been very intriguing subject of signal transmission. Longsought efforts of genetic screening based on the short-range silencing movement represented by, e.g., Atsuc2-hpPDS or Atsuc2-hpSul, in an intention to identify cellular components 
(a)

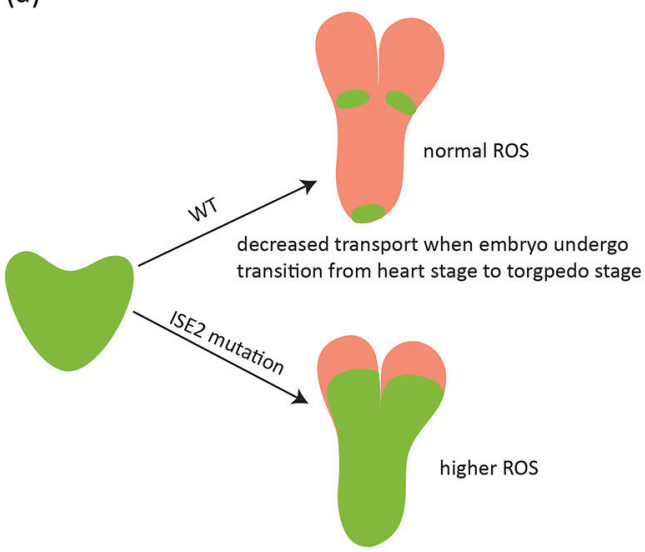

(b)
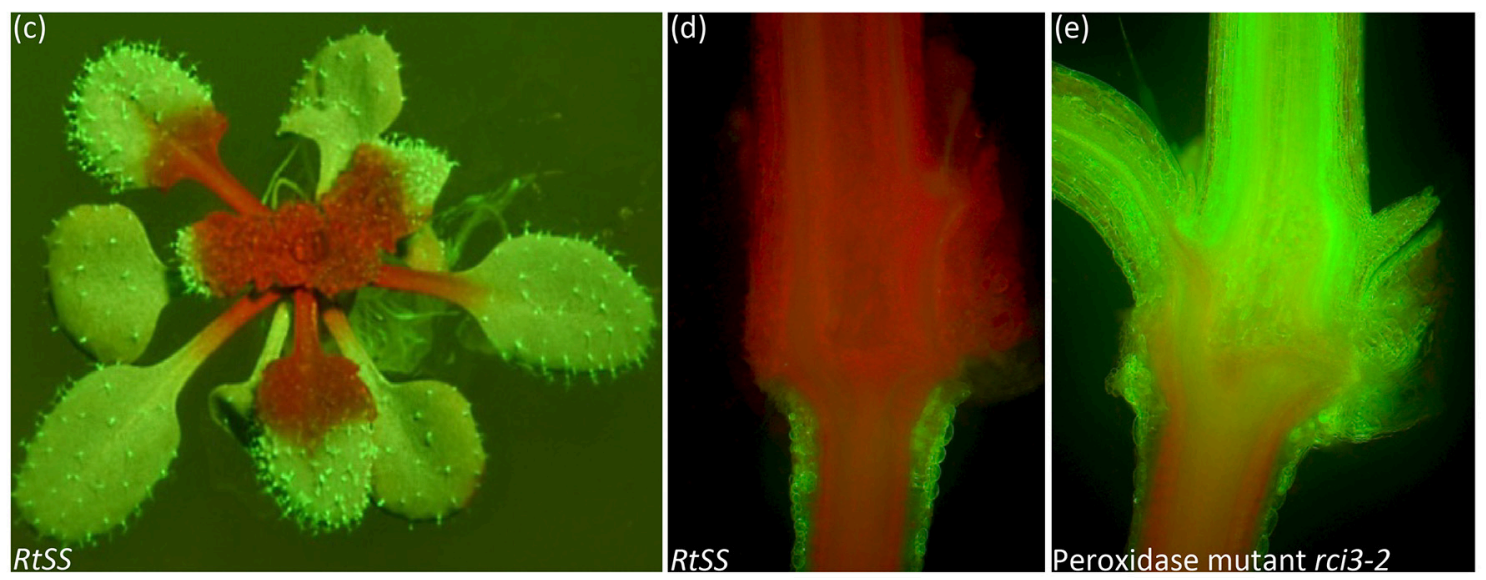

FIGURE 1 | Symplastic dye movement is associated with ROS. The symplastic dye $10 \mathrm{kd}$ F-Dextran moves freely at the heart stage of WT and ise2 mutant, but its movement is restricted at the torpedo stage due to the formation of symplastic domain. Higher ROS content in the ise 2 mutant lifts this restriction. Green depicts F-Dextran (a). In the epidermal/trichome (e/t) boundary, LYHC dye moves freely between the trichome cells, but cannot cross the e/t boundary into epidermal cell. Sodium azide, a known ROS-inducing agent can break this blockage. Yellow color depicts the LYCH. (c-e) A root-to-shoot silencing system (RtSS) demonstrates the long-distance movement of small RNA-mediated gene silencing movement. (c) An RtSS plant shows the silencing pattern after 15-day Dex induction.

(d,e) Longitudinal sectioning of RtSS has shown that silencing front moves from the root to the shoot (d), but the mutation in type III peroxidase RCl3 (R145K) heavily retards the movement (e). (a,b) were drawn according to the description by Kim I. et al. (2002) and Christensen et al. (2009) respectively. (e) was reprinted from Liang et al. (2014) under a Creative Commons Attribution License granted to Peer J.

constituting either cytoskeletal features or cell channels result in the identification of genetic factors that are mainly constituting the silencing machinery or silencing pathways (Melnyk et al., 2011). Besides, the time the silencing itself takes to travel through (assumed in the phloem system) is surprisingly much longer than photoassimilates in the phloem sap (Table 1). These situations leave the traffic control of mobile silencing signal through PD unsettled, and also translate into a need to tackle the issues around the way the silencing movement may take.

In an effort to mimic the grafting system, Liang et al. (2012) established a root-to-shoot long-distance mobile silencing system (RtSS) in which the initial site of silencing signal generation is spaciously separated from the signal receiving tissue (Liang et al., 2012), thus enabling to follow the route, monitor the time, and tease out the details for an upward systemic silencing. Indeed, a reiterated cell-to-cell silencing movement was observed making up the upward long-distance silencing. As discussed in previous section, the symplastic domain validated by symplastic dye makes its own hurdle on the movement of this small RNA-mediated gene silencing, resulting in the variation of movement rate during the course of systemic spreading (Table 1); for example, the slower movement in the hypocotyl-epicotyl junction than in the hypocotyl.

Forward genetic screening on RtSS, aiming to understand movement control imposed by PD and/or symplastic domain, identified tsg1 (Tiao-shan-gong 1, meaning in Chinese the mountain porter who facilitates transport over a mountain) mutant that shows only deficiency in the silencing movement while maintaining the production of silencing signal (Liang et al., 2014). Genetic and molecular studies aided by genome re-sequencing revealed that $t s g 1$ is an allele of $r c i 3$ gene which encodes type III peroxidase (POX) enzyme. An Arg to Lys substitution in a highly conserved motif in the RCI3 peroxidase resulted in the reduced hydrogen peroxide level in the mutant 


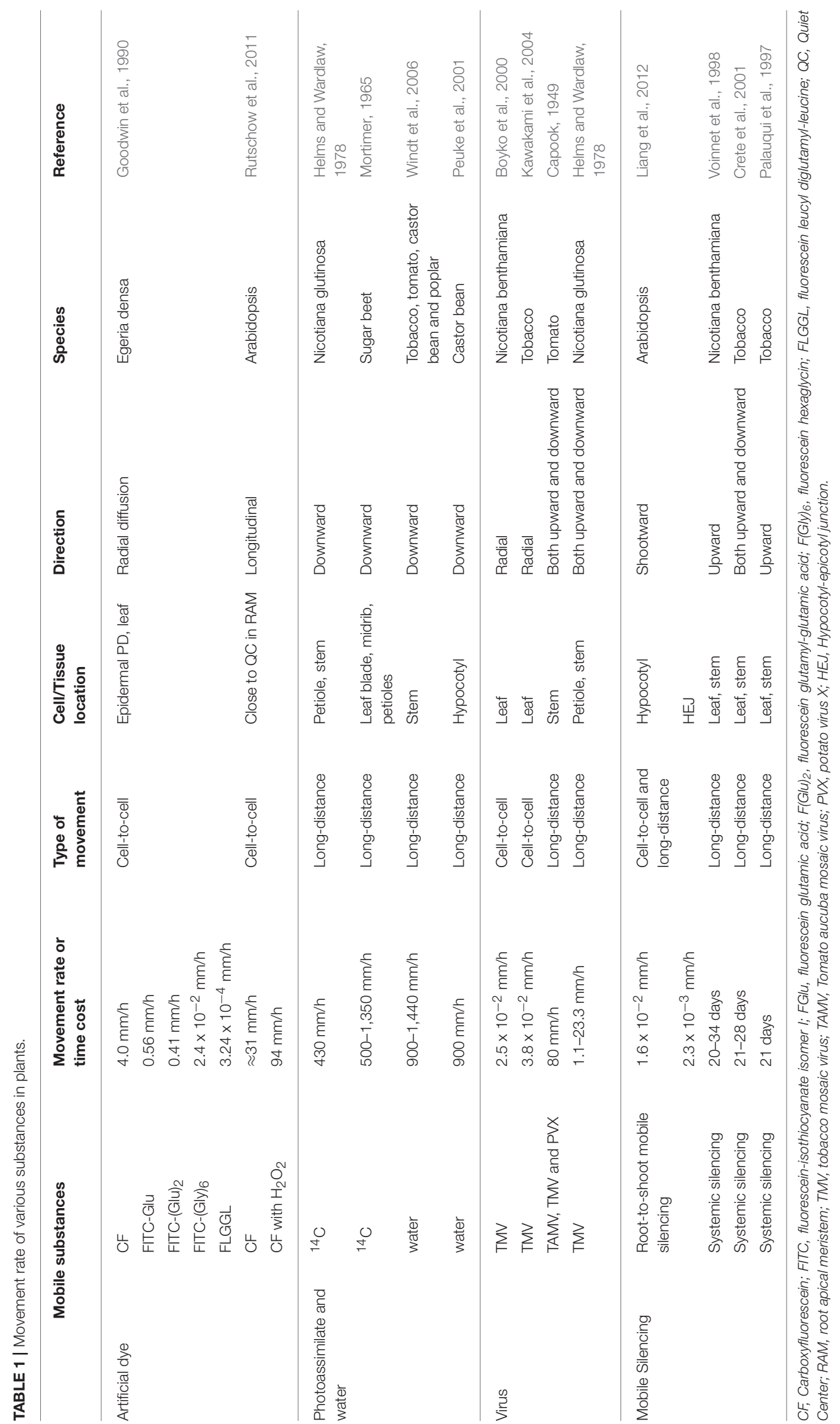


line, in agreement with the function of POX which can regulate $\mathrm{H}_{2} \mathrm{O}_{2}$ level through peroxidative and oxidative cycle (Figure 2) (Berglund et al., 2002; Passardi et al., 2004b). Most remarkably, direct replenishment of $\mathrm{H}_{2} \mathrm{O}_{2}$ to plant growth medium not only can restore silencing movement in the mutant, but also augment the rate of silencing movement in RtSS system (Liang et al., 2014) and the range of vascular silencing (Liang et al., 2014) in JAP3 line (Smith et al., 2007). Conversely, depletion of $\mathrm{H}_{2} \mathrm{O}_{2}$ in plant growth medium by Catalase or $\mathrm{MnO}_{2}$ catalyst can simply and efficiently reduce the silencing movement in both RtSS and JAP3 line (Liang et al., 2014), unambiguously pinning down the role of $\mathrm{H}_{2} \mathrm{O}_{2}$ in small RNA-mediated gene silencing movement.

The silencing front moves through hypocotyl to shoot in a way of cell-to-cell transmission, and spreads-analogously to the PD-mediated symplastic dye movement-with considerable resistance into symplastic domains, such as hypocotyl epidermis (Duckett et al., 1994) and the hypocotyl-epicotyl junction (Liang et al., 2012). Thus, it's legitimate to assume that the cell-tocell channel or PD is the route for silencing RNAs migration. Immunogold-labeling assay and Cerium(III) cytochemical TEM (Transmission electron microscopy) assay respectively localized the POX and $\mathrm{H}_{2} \mathrm{O}_{2}$ to $\mathrm{PD}$ vicinity and cambial cell wall in the form of punctate aggregates associated with PD (Ehlers and van Bel, 2010), suggesting the role of $\mathrm{H}_{2} \mathrm{O}_{2}$ and/or $\cdot \mathrm{OH}$ in $\mathrm{PD}$-associated process. Earlier insights revealed by many biochemical studies that elevation or decreasing of $\mathrm{H}_{2} \mathrm{O}_{2}$ resulted in cell wall loosening or stiffening (Fry, 1998; Schweikert et al., 2000; Schopfer, 2001; Liszkay et al., 2004; Müller et al., 2009; Kunieda et al., 2013) led the authors to propose a new model in which the PD-mediated transport is modulated through cell wall remodeling (Liang et al., 2014). In this model, ROS molecules like $\mathrm{H}_{2} \mathrm{O}_{2}, \cdot \mathrm{OH}$ are working as biochemical scissor, cleaving cell wall polymers, altering the cell-wall networks, and inevitably changing the passage of PD imbedded in the cell wall (Figure 2). This model emphasizes the role of ROS in apoplastic space and, for the sake of simplicity, has not considered the ROS signaling happening in the symplastic domain due to lack of experimental data. Thus, further investigation regarding to the intracellular aspects of ROS-initiated cascade (Mangano et al., 2016; Schmidt et al., 2016; Kimura et al., 2017) will reveal novel insights into the interaction between symplastic and apoplastic ROS signaling pathways.

\section{PROTEIN DIFFUSION IS ASSOCIATED WITH ROS}

It is generally established that specification of cell types through cell proliferation and differentiation largely depends on positional cues (Sessions and Yanofsky, 2001; Van Norman et al., 2011), which are hypothesized to exert their non-cell autonomous effects from a certain distance. Plant meristemmaintaining factors, such as WUSCHEL (WUS) (Yadav et al., 2011), KNOTTED-1 (KN1) (Lucas et al., 1995; Kim J. Y. et al., 2002), SHORT-ROOT (SHR) (Nakajima et al., 2001; Gallagher et al., 2004), TMO7 (Schlereth et al., 2010), are produced either locally or in a spatially discrete way, but can move in a short distance into neighboring cells to initiate downstream regulatory programs, thereby exemplifying the typical positional signaling mediated by mobile transcriptional factors (see reviews by $\mathrm{Wu}$ and Gallagher, 2012; Han et al., 2014; Long et al., 2015). The immediate question would be of interest to pinpoint the pathways whereby the mobile proteins are signaling their effects, e.g., the secretory pathway or PD pathway. Genetic screening on pSUC2::GFP system in which the distribution of GFP fluorescence is expanded from phloem into RAM due to a free GFP protein diffusion (Imlau et al., 1999) (Figure 3) identified gain-of-function mutation in CALS3 gene whose product catalyzes the polymerization of $\beta$-1,3-linked D-glucose or callose formation (Vatén et al., 2011). Mutation in CALS3 gene not only congealed GFP diffusion, but also substantially retarded root growth. Presumably, the phenotypic change in CALS3 gainof-function mutant resulted partially, at least, from the impaired movement of SHR protein and microRNA miR165 (Vatén et al., 2011; Wu et al., 2016), as the aperture of PD was decreased by increased callose deposition in the PD neck of mutant, which is exactly consistent with tremendous studies on the effect of callose on PD conductivity (see reviews by Roberts and Oparka, 2003; Chen and Kim, 2009; Zavaliev et al., 2011; Burch-Smith and Zambryski, 2012; De Storme and Geelen, 2014; Sager and Lee, 2014). Likewise, in the shoot tip, PD aperture reduction by CALS3m-directed callose deposition in the SAM restricts WUS protein movement from organizing center to stem cells residing in the outermost cell layers (Daum et al., 2014), leading to developmental defects similar to wus mutant. These studies have clearly assigned the rout for mobile transcriptional factor, and positional signaling through $\mathrm{PD}$ is indeed playing very important role in cell division and cell identity, thus tissue patterning (Otero et al., 2016).

An earlier independent EMS screening on pSUC2::GFP system with the same aim to uncover mutant showing reduced GFP traffic, pointed to a new regulatory pathway linked to redox homeostasis (Benitez-Alfonso et al., 2009). Benitez-Alfonso et al. demonstrated that GFP movement in the phloem-RAM interface ground to a halt in an epiallele of gat1 gene encoding a plastid-localized $m$ type thioredoxin (Figure 3), which essentially contributes to the regulation of chloroplast redox state (Vieira Dos Santos and Rey, 2006; Serrato et al., 2013; Nikkanen and Rintamäki, 2014; Buchanan, 2016). Indeed, examination on ROS level in this mutant detected an elevated oxidative staining with $3,3^{\prime}$-diaminobenzidine (DAB) compared to the wild type plant, apparently contradicting to these findings (Stonebloom et al., 2009; Rutschow et al., 2011; Liang et al., 2014) in which the increased ROS level are positively associated to PD-mediated transport. As ISE1, ISE2, GAT1 protein are localized in different organelles, one approach to reconcile this contradiction is to determine the sub-cellular redox state indicated by the redox-sensing green fluorescent protein fused with specific compartment-targeting signal; a higher oxidized state of mitochondria in the ise 1 mutant or in WT plants treated with Salicylhydroxamic acid (SH) and a reduced chloroplast redox in ise 2 are all positively correlated to plasmodesmal transport whereas oxidized state of chloroplast in paraquattreated WT plants resulted in decreased plasmodesmal transport 


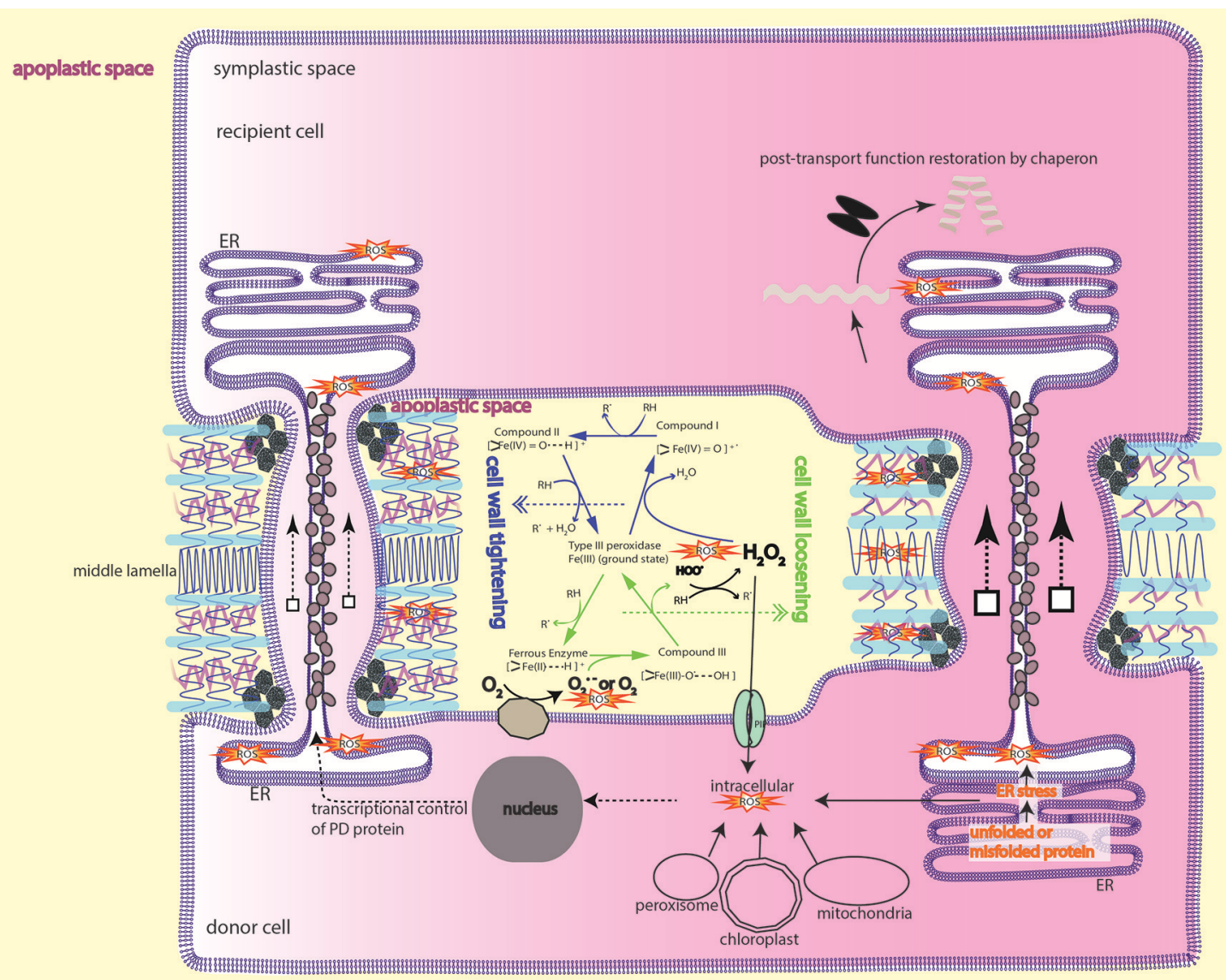

FIGURE 2 | Peroxidase-catalyzed cell wall remodeling dictates PD transport. In the apoplastic space (light yellow), type III peroxidase (POX) performs peroxidative cycle (blue arrows) and oxidative cycle (green arrows) to regulate $\mathrm{H}_{2} \mathrm{O}_{2}$ and superoxide/O2 level. Apoplastic ROS from the two cycles lead to cell wall tightening or loosening by crosslinking or depolymerizing cell wall components, thereby shrinking or enlarging the plasmodesmatal passage. Apoplastic $\mathrm{H}_{2} \mathrm{O}_{2}$ can also, through aquaporins-mediated transmembrane transport, enter the cytoplasm to initiate downstream signaling events, e.g., MAPK cascade signaling and cytoskeletal remodeling, resulting in membranous protrusion (see the section ROS are required to form intercellular/interorganelle bridge for the details). ROS imbalance inflicted by mutation in ISE1, ISE2, GAT1 localized in the subcellular compartments also impacts on intercellular transport. It's currently unknown whether or how ROS from subcellular compartments contribute to apoplastic ROS pool. Protein that moves through PD sleeve may be subject to ER stress-induced ROS, thus requires a post-movement refolding (details in the text). The peroxidase/oxidase cycling was adapted from Berglund et al. (2002) with the permission from Rightslink ${ }^{\circledR}$.

irrespective of the redox states of either mitochondria or cytoplasm (Stonebloom et al., 2012). The decreased PD transport in gat 1 mutant seems concordant with the proposed model (Stonebloom et al., 2012) as paraquat-treated pSUC2::GFP plants showed exactly the same phenotype to gat1 mutant (BenitezAlfonso et al., 2009). Comprehensive work such as direct comparison between mutants, e.g., the ise1 (Stonebloom et al., 2009), ise2 (Kobayashi et al., 2007), gat1 (Benitez-Alfonso et al., 2009), dse1 (Xu et al., 2012) with deficiency in PD transport, may be needed to construct a clearer picture of what effects the site of ROS production may inflict on PD conductance.

\section{Different ROS and Their Possible Roles}

The question of whether different ROS have different roles in regulating $\mathrm{PD}$ transport remains a mystery, but looms, indeed, large, which can be inspired from the findings that superoxide and hydrogen peroxide differently regulate cell proliferation, cell differentiation, and root growth in Arabidopsis (Dunand et al., 2007; Tsukagoshi et al., 2010; Müller et al., 2015). Tsukagoshi et al. (2010) reported a novel pathway involving three peroxidases (Per39, Per40, Per57) that function to balance the distribution of hydrogen peroxide and superoxide in the transition zone of cell proliferation and cell differentiation. Disturbance of ROS level by overexpression or disruption of peroxidase, can alter the ROS homeostasis in the transition zone, leading to increased or decreased root meristematic cell number. Interestingly, negative regulation of peroxidase expression requires a mobile transcriptional factor, UPBEAT1, which appears to move from root cap to elongation zone to repress peroxidase transcription and allows $\mathrm{H}_{2} \mathrm{O}_{2}$ accumulation in the differentiated zone. In the light of abovementioned evidence on the role of ROS in PD and recent evidence on the role of ROS in root development (Müller et al., 2015; Orman-Ligeza et al., 2016; Yu et al., 2016), it is compelling to speculate that developmental regulation 
A

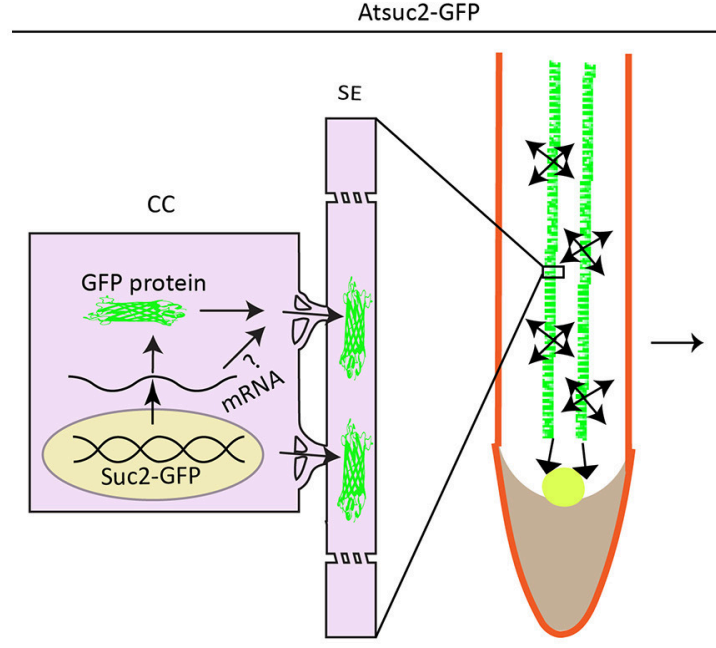

B

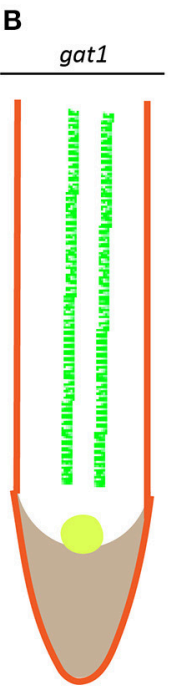

C

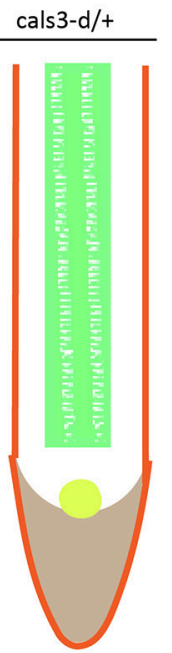

FIGURE 3 | Protein unloading from phloem to surrounding cells in root is associated with redox homeostasis. GFP is specifically expressed in the companion cell under the control of AtSuc2 promoter. It's not retained in the companion cell but rather disperses into sieve element (SE) and other parts of roots including stele, cortex, RAM (round circle), and root cap (A). mRNA of GFP is less likely to move into surrounding cells to be translated into fluorescence signal as plants harboring either bigger size of GFP or subcellular targeted GFP only show green fluorescence in the companion cells. Loss-of-function mutation in thioredoxin gene GAT1 for redox regulation (B), or gain-of-function mutation in callose synthase gene Cals3 shows defective GFP trafficking (C). (A-C) were drawn according to the description by Imlau et al. (1999), Benitez-Alfonso et al. (2009), Vatén et al. (2011) respectively.

via ROS signaling in root is, at least partially, coming from the oxidative/reductive impact on PD transport. However, this speculation should be tested, and particularly the nature of ROS in relation to cell types and PD function needs to be delineated.

\section{ROS Stress, Chaperon, and Intercellular Protein Movement}

Another different approach involving the KN1 movement makes a surprising finding, where KN1 movement requires chaperone protein CCT8, a type-II chaperonin subunit (Xu et al., 2011) (Figure 4). Xu et al. (2011) further suggested that the whole chaperonin complex, known as TRiC/CCT complex, consisted of two rings with each having eight paralogous subunits (CCT1-8) (Horwich et al., 2007; Hartl et al., 2011), is required for unfolding and intercellular transport of $\mathrm{KN} 1$ protein. In addition to KN1 movement, movement of TRANSPARENT TESTA GLABROUS1 (TTG1) and, even external intruder such as oilseed rape mosaic virus (ORMV) also requires this complex (Xu et al., 2011; Fichtenbauer et al., 2012).

Most notably, CCT8 needs to be present in the destination cell, rather than the donor cell, to make the translocated GL1KN1 fusion functional, however, this fusion, if natively expressed in the destination cell (de novo protein folding), is agnostic to CCT8 chaperonin (Xu et al., 2011). Therefore, re-folding after translocation through $\mathrm{PD}$ is critical for mobile protein to fulfill its function in new place. But, these observations, on the other hand, inevitably cast new thoughts on such questions as why chaperonin is needed for post-translocation re-folding, or whether there is any modification occurring to unfolded amino acid chain during passage through PD. Currently, there is no clue to these questions from literature, however, in the perspective of redox regulation on $\mathrm{PD}$, it's tantalizing to conceive that the importance of chaperonin complex in $\mathrm{PD}$-mediated protein movement is likely two-fold: (1) to unfold before transport and refold the impaired amino acid chain due to oxidative stress around PD after transport and (2) to protect mobile protein from redox fluctuation. Furthermore, protein folding/unfoldinginduced endoplasmic reticulum (ER) stress, or more precisely the unfolded/misfolded protein-induced ER stress has been proposed to be a significant source of cellular ROS (Malhotra and Kaufman, 2007; Rutkowski and Kaufman, 2007; Santos et al., 2009), estimated to account for $25 \%$ of cellular ROS in the yeast Saccharomyces cerevisiae ( $\mathrm{Tu}$ and Weissman, 2004). The similar mechanisms seem to operate in plants as well (Onda and Kawagoe, 2011; Aller and Meyer, 2013; Ozgur et al., 2014). Since ER sleeve runs through PD (Figure 2), ROS production from this process could be exploited to facilitate intercellular movement. Further studies need to be explored to reveal how chaperon protein help to move through PD channel and in what mode chaperon protein is incorporated with ROS to regulate intercellular communication.

\section{ROS ARE REQUIRED TO FORM INTERCELLULAR/INTERORGANELLE BRIDGE}

\section{ROS Induction of Cellular Membrane Protrusions}

Tunneling nanotubes (TNTs), usually considered as counterpart to $\mathrm{PD}$, have recently been discovered in a variety of cell types 


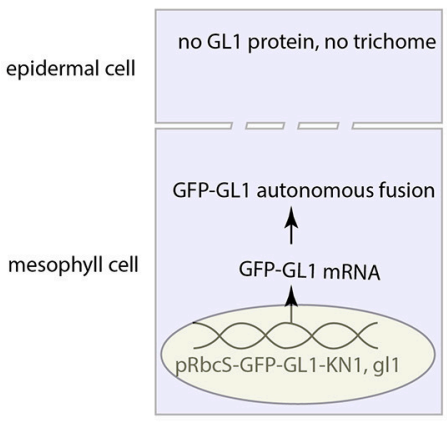

pRbcS-GFP-GL1, gl1 mutant

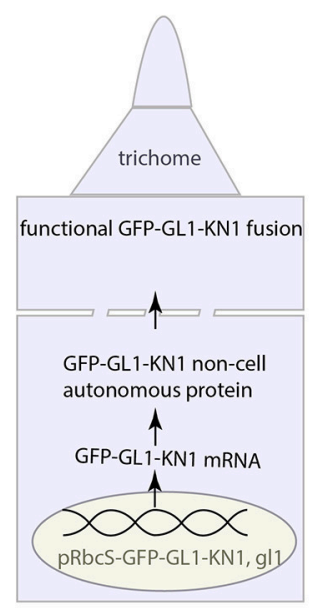

pRbcS-GFP-GL1-KN1, gl1 mutant

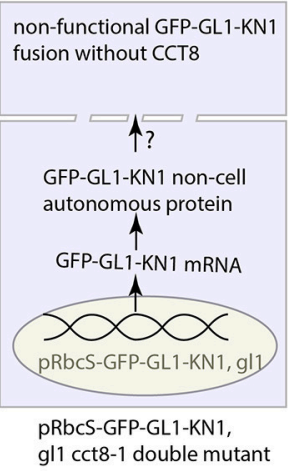

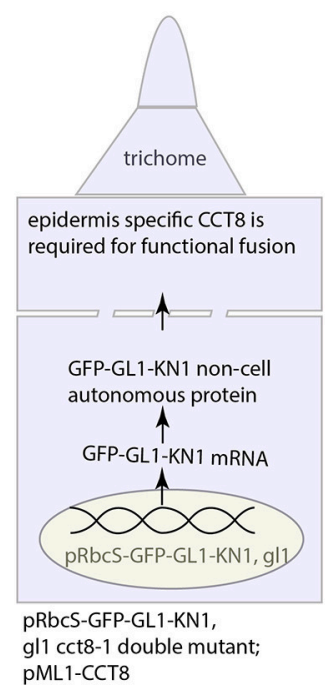

FIGURE 4 | Intercellular KN1 movement through PD requires a post-movement refolding, which could result from ER stress. The non-cell autonomous feature of KN1C (trafficking domain of KN1) protein renders the GFP-GL1-KN1C fusion as a movement protein that moves from mesophyll cell to epidermal cell, whence the GL1 part in the fusion initiates the developmental program for trichome specification. Chaperonin CCT8 is required in the destination cell, in this case the epidermal cell, to refold the post-movement protein. This figure was drawn based on the description by Xu et al. (2011).

(Rustom et al., 2004; Gerdes et al., 2007; Gurke et al., 2008; Rustom, 2009). These intercellular bridges that link mammalian cells are at play in transmitting a range of signals involved in developmental processes and spreading pathogens as well (Gerdes and Carvalho, 2008; Eugenin et al., 2009; Hase et al., 2009; Marzo et al., 2012; Abounit et al., 2016; Hashimoto et al., 2016; Victoria and Zurzolo, 2017). Thus, how TNTs are contributing to intercellular transport is becoming a very interesting, targeted topic since their discovery (Rustom et al., 2004). Accumulating evidence has shown that hydrogen peroxide can not only promote the formation of TNTs within the same cell type, e.g., between rat primary neurons, astrocytes (Zhu et al., 2005; Wang et al., 2011), and mouse CAD cells (Gousset et al., 2013), but also between heterozygous cell type, e.g., rat primary astrocytes and C6 glioma cells when co-cultured (Zhang and Zhang, 2015). Actually, more than hydrogen peroxide, oxidative stress induced by oxidant methylglyoxal and menadione can also promote TNTs formation in human peritoneal mesothelial cells (Ranzinger et al., 2014; Rustom, 2016) and rat astrocytes (Zhu et al., 2009) respectively. Moreover, a recent study has shown that movement of alpha-synuclein through TNTs is accompanied by increased ROS, suggesting that ROS could facilitate intercellular protein transport by increasing the number of TNTs (Abounit et al., 2016).

Notwithstanding these clear phenomena, the mechanisms underlying ROS-induced TNTs formation are just emerging from the perspective of their structural composition. Because TNTs are mainly actin-filled membrane protrusions (Austefjord et al., 2014), the inductive formation by ROS could be attributed to the effects on actin dynamics.

Indeed, cytoskeletal behaviors, under ROS stress, is widely shown to be altered (Raghu et al., 1986; Zhao and Davis, 1998;
Gellert et al., 2015; Wilson and González-Billault, 2015; Xu et al., 2017), including actin polymerization, filament assembly, branching, cytoskeletal reorganization, and dynamic interactions with cytoskeletal regulators. These behavioral changes stem from either the direct oxidation of actin by ROS, or the ROS-initiated signaling, or both. Topologically exposed in the cytoplasm, some amino acid residues (e.g., Met 44, 47, 355, Cys 374) in actin and other cytoskeletal components are liable to oxidative attack (Lassing et al., 2007; Fedorova et al., 2010; Hung et al., 2011; Wilson et al., 2016), thereby inhibiting actin polymerization or association with other proteins (Dalle-Donne et al., 2002, 2003; Landino et al., 2002, 2007). These results are insightful; however, there are few reports showing the impairment of membrane protrusions are the direct result of actin oxidation. Part of this reason could be due to the powerful in vivo antioxidant system that can reverse the oxidized form. For example, under $\mathrm{H}_{2} \mathrm{O}_{2}$ treatment, actin can be kept in reduced form by thioredoxin-1 (Trx1) through its interaction with cysteine 62 of actin (Wang et al., 2010), thus antagonizing the direct oxidation. Similarly, for the oxidized Met, a methionine sulfoxide reductase SelR can reduce the oxidized Met 44 (Hung et al., 2013).

\section{Molecular Signaling in TNTs Formation}

Apart from the direct interplay between ROS and antioxidant on the actin behavior, indirect cascade, or the ROS-initiated signaling could play important roles in dictating the actin-driven membrane protrusions. A pioneer work demonstrated that $\mathrm{H}_{2} \mathrm{O}_{2}$ induces TNTs-like protrusion formation by promoting actin polymerization and colocalzation of myosin $\mathrm{Va}$ and F-actin in the newly formed protrusions in primary rat astrocytes (Zhu et al., 2005). What's more, the property of astrocytes plasma membrane is also altered under ROS treatment, which seems 
not to be from the sheer oxidative damage on membrane, rather to be mediated by cytosolic phospholipase $\mathrm{A}_{2} \quad\left(\mathrm{CPLA}_{2}\right)$ ( $\mathrm{Zhu}$ et al., 2009). Further biochemical experiments suggested that $\mathrm{H}_{2} \mathrm{O}_{2}$-triggered phosphorylation of p38 MAPK and ERK1/2 (extracellular-signal-regulated kinase $1 / 2$ ) is the key to protrusion formation as specific inhibitors of p38 MAPK and ERK can nearly abolish the $\mathrm{H}_{2} \mathrm{O}_{2}$-induced TNTs formation (Zhu et al., 2005, 2009). p38 MAPK and ERK1/2 are very import players in connecting various signaling pathways and involved in various fundamental processes (see reviews by Roux and Blenis, 2004; Shaul and Seger, 2007; Xu et al., 2014), so the question lingers about the MAPK cascade signaling specificity to TNTs formation. Fortunately, identification of the molecular players acting seemingly downstream of ERK1/2 could-at least partially-answer this question. A TNTs-like localized protein $\mathrm{M}-\mathrm{Sec}$ induces de novo actin-containing protrusions through interaction with the activated small GTPase RalA and, mediation by RalA-exocyst complex (Sugihara et al., 2002; Hase et al., 2009). The exocyst complex has been shown to be directly involved in actin remodeling; one subunit of exocyst, Exo70, interacts with the Arp 2/3 complex (a key machinery for the generation of the filamentous actin network) to promote actin branching, resulting in membrane ruffling or protrusion (Zuo et al., 2006; Liu et al., 2009). A later discovery that ERK1/2 can directly phosphorylate the exocyst subunit Exo70 to enhance the complex assembly in response to EGF (epidermal growth factor) (Ren and Guo, 2012), established the link between ROS-initiated ERK1/2 signaling and M-Sec-RalA-Exocyst complex (Figure 5). Actually, in a similar situation to TNTs formation, ERK is also required for EGF-stimulated protrusion in human mammary epithelial cells. In this case, ERK promotes the lamellipodia protrusion by directly phosphorylating the WAVE2 Regulatory Complex (WRC), which then activates the Arp2/3 complex for actin assembly together with activated WAVE2 and Abi1 (activation by the ERK phosphorylation as well) (Mendoza et al., 2011). The mobilizing force to drive actin network remodeling may come from the myosin motor (Nambiar et al., 2010) that has been widely shown in the recent reports (Bishai et al., 2013; Lou et al., 2015; Yochelis et al., 2015; Saczko-Brack et al., 2016), so what factor, if there is any, is directing the force to this process? Interestingly, a recent report has pointed out that the ERK signaling could provide a clue in which ERK promotes lamellipodia protrusion by lifting the sequestration of myosin $1 \mathrm{E}$ by SH3P2 via phosphorylating its Ser 202, thus resulting in myosin-actin association at the leading edge of the human MKN1 tumor cell (Tanimura et al., 2016; Tanimura and Takeda, 2017).

Another study also showed that TNTs are induced by $\mathrm{H}_{2} \mathrm{O}_{2}$ in rat hippocampal astrocytes and neurons respectively. Genetic manipulation demonstrated that $\mathrm{p} 53$ is required for TNTs development, and that Akt is involved in TNTs induction by $\mathrm{H}_{2} \mathrm{O}_{2}$. Ly294002 and rapamycin, the inhibitor of PI3K and mTOR (the both are p53-responsive genes), respectively, can effectively quench the TNTs induction (Wang et al., 2011). Actually, an earlier report showed that mTOR together with RICTOR regulated actin organization by modulating the phosphorylation of Protein Kinase $\mathrm{C} \alpha(\mathrm{PKC} \alpha)$ (Sarbassov et al., 2004). These collective data suggest the PI3K-Akt-mTOR signaling pathway is another key mechanism to regulate TNTs induction (Wang et al., 2011) through activating M-sec (Figure 5), or that the p38 MAPK and PI3K-Akt-mTOR might crosstalk to regulate their formation (Xu et al., 2014). Therefore, future studies in light of dissecting the relationship between the ROS-initiated p38, ERK, and PI3K-Akt-mTOR signaling are needed to advance our knowledge of TNTs formation under the direction of such complex signaling networks.

\section{Actin Cytoskeleton-Based Cellular Protrusions}

Since actin cytoskeleton plays a crucial role during TNTs formation (Austefjord et al., 2014), it would be of interest to know whether ROS-triggered effects could be extrapolated to other actin-based membraneous protrusions, e.g., cytonemes (Ramírez-Weber and Kornberg, 1999; Hsiung et al., 2005), and actin-dependent outgrowth of neurite in neuron (da Silva and Dotti, 2002; Chia et al., 2016; Winans et al., 2016).

Remarkably, a physiological level of ROS sourced mainly from NOX and lipoxygenase is critical for neurite outgrowth; downregulation of ROS level with many different ROS scavengers caused the disassembly of actin cytoskeleton, resulting in reduced neuronal extension (Munnamalai and Suter, 2009). Different to the ROS signaling in TNTs outgrowth in the earlier reports by Zhu et al. (2005), Hase et al. (2009), and Wang et al. (2011), the signaling events for neuronal outgrowth are consisting of interactions between Rac and Rho GTPase-involved pathways (Figure 5) (Nimnual et al., 2003; Munnamalai and Suter, 2009; Chianale et al., 2010; Winans et al., 2016). Noteworthily, the Rac and Rho pathways are not tailored for neuronal outgrowth; they, together with Cdc42 and downstream componensts WAVE, WASP, and Arp2/3, are also required for TNTs biogenesis in macrophage (Hanna et al., 2017), and cytoplasmic protrusions during Xenopus embryonic development (Tahinci and Symes, 2003). Further studies on the in vitro neurite outgrowth have found that the protrusions, under certain circumstances, are also promoted by Akt-mTOR pathway (Jin et al., 2012) and p38 MAPK signaling pathway (Sarina et al., 2013), suggesting that neruronal outgrowth, similar to TNTs formation, can be achieved through diversified pathways. The wide availability of versatile signaling pathways may reflect the effective response of intercellular movement via formation of intercellular bridge to numerous environmental stimuli which more or less cause redox fluctuation. And eventually, the responsive node is converged on the actin cytoskeleton or other cytoskeletons possibly in accordance with the type of cellular protrusions (Figure 5).

Cytonemes are another type of intercellular bridges, similar to TNTs in shape, but distinct from TNTs in the contact sitesopened in the TNTs and closed in the cytonems. Since cytonemes are actin-based structure, it is plausible that cytonemes formation may be also subject to ROS regulation. This corollary does not guarantee an exact scenario, but a similar one. Actually, nitric oxide (NO), another type of reactive species (RNS, reactive nitrogen species), can drastically promote the formation of cytonemes on the surface of human neutrophil (Galkina et al., 2005) for targeting their prey at a distance (Galkina et al., 2009), 
A TNT formation in mammlian cell

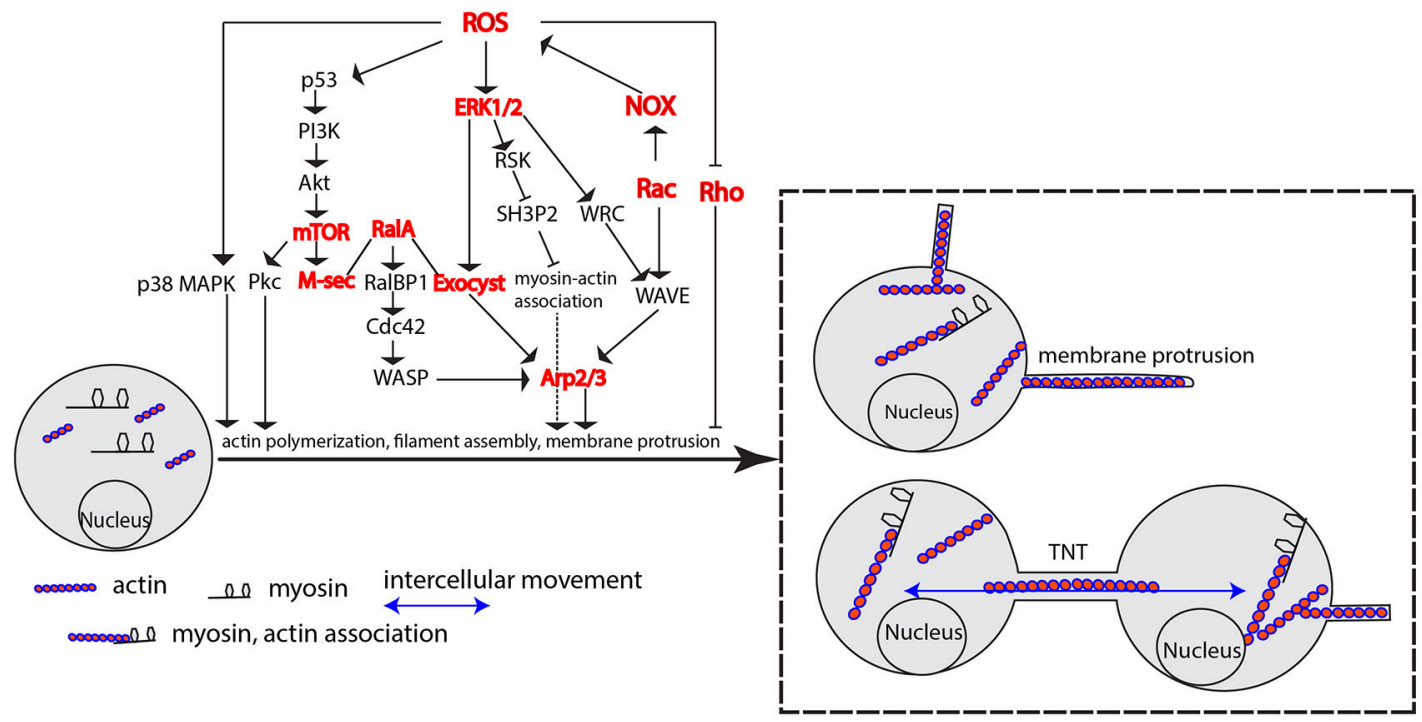

B suborganelle bridge formation in plant cell

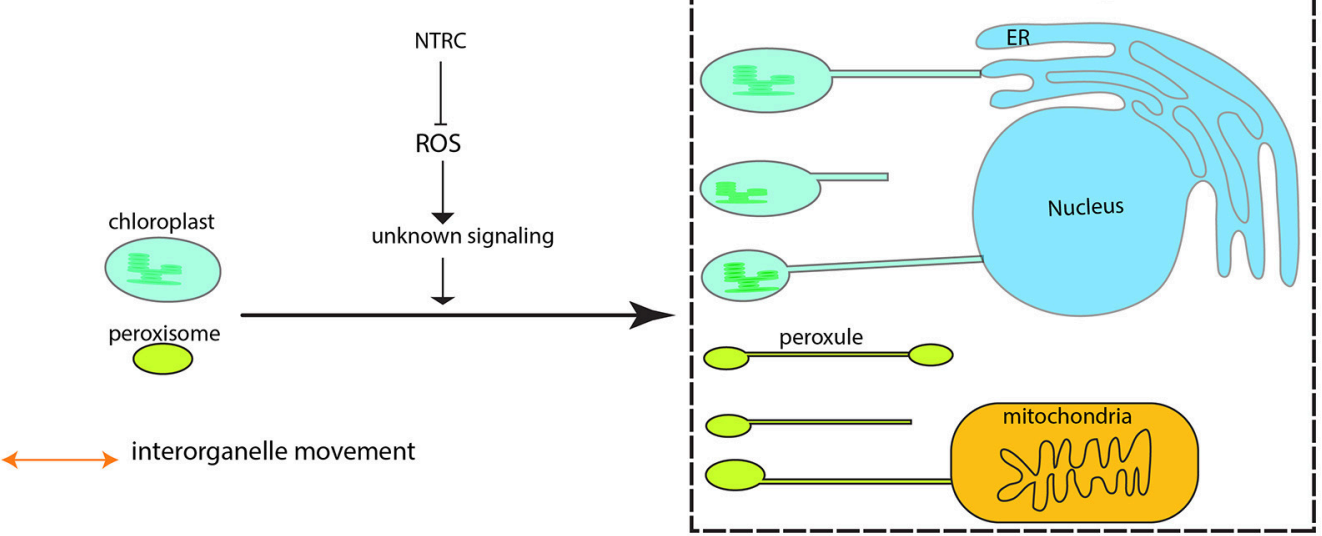

FIGURE 5 | ROS-induced formation of membrane protrusion, intercellular and interorganelle bridge. (A) At physiologically higher ROS levels, TNTs are formed between cells via cytoskeleton-based (e.g., actin, myosin) membrane protrusion. ROS-induced diversified pathways including p38 MAPK, PI3k-Akt-mTOR signaling, ERK1/2 signaling, Rho GTPases family, and M-Sec-RalA-Exocyst complex, are shown to promote membrane protrusions mainly via Arp2/3-mediated actin cytoskeletal remodeling. The cooperative association between myosin and actin that is activated by ERK signaling plays an important role in mobilizing various related components and mediating membrane-cytoskeleton coordination. (B) In plant cells, the membrane-encircled organelles, e.g., the chloroplast and peroxisome, can form inter-organellar bridge between the same type of organelle (the stromule and peroxule) and different types of organelles under higher ROS condition. Repression of NTRC leads to increased stromules. The signaling mechanism is currently unknown. Arrows may not denote direct activation. Several key nodes in the signaling networks are colored in red, and Arp1/2 complex, Exocyst complex, NOX, ERK, p38 MAPK, Rac and Rho are also encoded in plant genomes. p38 MAPK, p38 mitogen-activated protein kinase; Pkc, protein Kinase C; PI3K, phosphatidylinositol-3-kinase; AKT, protein kinase B; mTOR, mammalian target of rapamycin; M-Sec, Myeloid and M cells-expressing Sec6 homolog, also known as TNF alpha-induced protein 2, or Primary response gene B94; RalA, Ras-related protein Ral-A; RalBP1, RalA-binding protein 1; Cdc42, Cell division control protein 42 homolog; WASP, the Wiskott-Aldrich Syndrome protein; ERK1/2, extracellular signal-regulated kinase 1; Exocyst, an octameric complex; RSK, ribosomal S6 kinase; SH3P2, Src homology-3 (SH3) domain-containing protein 2; Arp2/3, actin-related complex 2/3; WRC, WAVE2 Regulatory Complex; NOX, NADPH oxidase; WAVE, WASP family verprolin-homologous protein; NTRC, NADP-thioredoxin reductase C.

and the inhibitor of nitric oxide synthase inhibit their extension without much impact on neutrophil spreading (Galkina et al., 2005). The exact inductive mechanisms are not fully addressed, however, based on the constituents of cytonemes, it's natural to speculate that NO may act through modulating cytoskeleton behaviors to extend cytomenes. Extensive studies have shown 
that nitric oxide synthase interacts with tubulin and actin cytoskeleton (Su et al., 2003, 2005; Kondrikov et al., 2006, 2010) and modulates their activity through tyrosine nitration and S-nitrosylation of target cytoskeletal proteins or cytoskeletonassociated proteins in both animals (Loesch et al., 1994; Aslan et al., 2003; Tedeschi et al., 2005; Thom et al., 2008; Zhang et al., 2015) and plants (Kasprowicz et al., 2009; Yemets et al., 2011; Yao et al., 2012; Blume et al., 2013; Rodríguez-Serrano et al., 2014). Thus, it's highly likely that these modifications on cytoskeleton, particularly the actin, could eventually impact on cytonemes formation.

However, this does not negate a possible role of ROS in cytonemes formation since several independent studies have shown that nitric oxide induces ROS production (Pieper et al., 1994; Lee et al., 2000; Patel et al., 2009). The NO-induced ROS can further trigger actin-based cellular protrusions, or alternatively, in vivo ROS generation could be achieved through the interaction of nitric oxide synthase with Rac protein (Jyoti et al., 2014), a key regulator of ROS production (Caron and Hall, 1998) (Figure 5). In fact, the NO-induced ROS pathway has been partially uncovered in another similar cellular protrusion in neutrophil. Neutrophil extracellular traps (NETs) are not surrounded by membranes, and appear thinner compared to cytonemes (Brinkmann et al., 2004). As in cytonems, NETs formation is induced with longer NO donor exposure, and this induction is dependent on the ROS generation from the mobilized NOX (Patel et al., 2010). Furthermore, genetic requirement of Rac and NOX for NETs formation reinforces the ROS part in the NETs protruding process (Lim et al., 2011; Stojkov et al., 2017).

The Rac and NOX components are also involved in the neutrophil chemotaxis by affecting actin behaviors. For example, NOX-dependent ROS negatively regulate actin polymerization via actin glutathionylation, and disruption of antioxidant enzyme glutaredoxin 1 (Grx1) leads to attenuated actin polymerization (Sakai et al., 2012). In mouse bone marrow neutrophil, Rac knockout significantly reduced superoxide level and neutrophil cell polarization toward a chemoattractant gradient (Roberts et al., 1999). Taken together, cytonemes formation, presumably via Rac-dependent actin cytoskeletal remodeling (Mitchell et al., 2008), might share the similar mechanisms to that underlying the TNTs and neuronal outgrowth (Figure 5). But before leaping to this conclusion, further study needs to be carried out to examine the relationship between RNS and ROS and, the crosstalk in signaling the membrane protruding process.

\section{Membrane Protrusions in Plant Cells}

As discussed above, the ROS-induced membrane protrusion via actin remodeling is widely seen in many different mammalian cell types. So, would an analogous situation occur in plants as well? Interestingly, rather than displaying the increased simple PD between cells, the ise 1 mutant with elevated ROS level as discussed earlier is developing more complex PD such as the twinned and branched PD (Burch-Smith and Zambryski, 2010), whose formation requires membrane insertion into pre-existing simple PD (Faulkner et al., 2008; Burch-Smith and Zambryski, 2012). Nevertheless, this process is much more complicated than the intercellular bridge formation between mammalian cells as it has to deal with cell wall remodeling, e.g., cell wall thinning (Ehlers and Kollmann, 2001; Ehlers and Westerloh, 2013). Thus, membrane protrusion induced by oxidative stress during complex PD formation may not typically exemplify the role of oxidative stress in this process, which is indeed the case in a new study on the formation of complex PD in Arabidopsis leaf epidermis (Fitzgibbon et al., 2013). Other relative simple membrane structure, without wall sophistication, could be more ideal to reflect the role of ROS in membrane protrusion in plants (see below for further discussion).

\section{ROS Induction of Interorganelle Structure: Stromule and Peroxule}

Some specialized membrane contact sites, or organelle extensions such as stromule, peroxule, matrixule (Mathur et al., 2012; Pérez-Sancho et al., 2016) - evidently without the complication of cell wall remodeling-present ideal platforms to address the mechanisms of membrane extrusions. Stromules are stromafilled tubules that may, in vivo, extend-analogous to TNTsalong actin microfilaments, myosin and ER (Kwok and Hanson, 2003, 2004; Gunning, 2005; Natesan et al., 2009; Sattarzadeh et al., 2009; Schattat et al., 2011). Stromule formation is known to be induced by different kinds of stresses including hydrogen peroxide (Gray et al., 2012). A recent study further elaborated this association. Brunkard et al. (2015) found that formation of stromule from photosynthetic chloroplast, not non-photosynthetic plastid or leucoplast, can be boosted by the chemicals that specifically elicit ROS production in the chloroplast. This result is further genetically reinforced by virus-induced gene silencing of the chloroplast-localized NADPthioredoxin reductase C (NTRC), which serves as reductant to reduce hydrogen peroxide (Brunkard et al., 2015); more than doubled stromule frequency in the NTRC silencing leaf of $N$. benthamiana is, therefore, presumably construed as the consequences of the ROS accumulation in the chloroplast (Brunkard et al., 2015; Hanson, 2015) (Figure 5). Since in vitro isolated chloroplast extends stromule independently of cytoplasmic niche (Brunkard et al., 2015; Ho and Theg, 2016), it would be very intriguing to see the ROS effect is still viable on the in vitro stromule formation, which could resolve the questions as to whether and/or how ROS effect is working through cytoplasmic niche.

A similar morphing response to ROS stress was also discovered in peroxisome's extension (Sinclair et al., 2009; Rodríguez-Serrano et al., 2016), namely the peroxule which is coined after stromule as these membrane protrusions are morphologically similar (Scott et al., 2007). The response is very rapid, and peroxule extension occurs within seconds of exposure to $\mathrm{H}_{2} \mathrm{O}_{2}$ and $\cdot \mathrm{OH}$ radicals (Sinclair et al., 2009). Similarly, high light stress, a condition in which cytosolic $\mathrm{H}_{2} \mathrm{O}_{2}$ elevation is induced, can bridge peroxisome-mitochondria contacts via peroxule (Figure 5). In addition, an irrelevant mutant to peroxule formation, the anisotropy1 defective in cellulose synthase (CesA) gene displays elevated internal $\mathrm{H}_{2} \mathrm{O}_{2}$ level, and at the same time has higher peroxule frequency compared to wild type plant 
(Jaipargas et al., 2016). Noteworthily, other ROS like singlet oxygen and superoxide seem not to instigate peroxule growth (Sinclair et al., 2009), suggesting peroxule formation may rely on specific ROS-dependent signaling pathway (Sinclair et al., 2009). The proposition is recently revealed that quick peroxule formation is achieved through NOX-generated ROS-mediated PEX11a expression - at least in the case of Cd stressing situation (Rodríguez-Serrano et al., 2016).

All of the accumulating evidence highlights a conservative phenomenon in which the membrane protrusions are subject to oxidative change, particularly $\mathrm{H}_{2} \mathrm{O}_{2}$ fluctuation, either internally or externally. In mammalian cells, the ROS-initiated signaling will eventually converge on the regulation of cytoskeleton that underpins the cellular protrusion. The key players in the signaling pathways that direct membrane protrusions are largely found in plant cells, e.g., the Arg2/3 complex (Yanagisawa et al., 2013), Rac and Rho family (Hassanain et al., 2000; Nagawa et al., 2010; Kawano et al., 2014), exocyst complex (Zhang et al., 2010), NOX (Wang et al., 2016), ERK (Cvetkovska et al., 2005; Furukawa et al., 2012), and p38 MAPK (Liu and He, 2017), implying that the signaling pathways in animals have meandered into the networks controlling the cytoskeleton remodeling in plant cells; an example is the exocyst complex is required for pollen tube growth (Bloch et al., 2016), for which extensive membrane dynamics and cytoskeletal remodeling are taking place at the tip of pollen tube (Cheung and $\mathrm{Wu}, 2008$; Kroeger and Geitmann, 2012; Qu et al., 2015). Although the exact mechanism for organellar extension is still under investigation, it's not hard to conceive that characterization of the structural compositions of these extensions including the membrane skeleton associated with them would represent a solid, but very challenging step toward the comprehension of such complicated process given the small size of these extensions. ROS-initiated signaling pathways can be further elaborated with the insights gained from TNTs studies.

\section{INCREASED OR DECREASED TRANSPORT VIA PD: AMOUNT TALKS}

ROS level has to be kept in a certain range to maintain a healthy cellular status, in which the intercellular movement alters with ROS concentration accordingly. As shown by Rutschow et al. (2011) and Liang et al. (2014), an uptick in hydrogen peroxide supplement can increase intercellular movement, but this effect can be reversed if the extra concentration has reached a very higher level of more than 3 or $6 \mathrm{mM}$. This phenomenon as well as the contradicted results from gat 1 and ise 1 mutant needs a further explanation although it might be associated with subcellular redox as discussed in previous section. Another possible way to work around this issue could borrow insights from recent work on pollen tube rupture and pathogen penetration.

\section{Oxidative Burst and Cell Wall Disconnection/Dissolution}

A ROS burst usually occurs under biotic/abiotic stress in order to kill invaded pathogen or trigger hyper-sensitive cell death to protect plants from detrimental effects induced by stressors. Such occurrence is a dangerous theme to plant itself, so employment of high ROS for plant normal development is thought to be rare. However, recent study reported that pollen release from the tube into the female gametophyte during reproductive process requires the cell wall rupture of pollen tube, which is achieved via a NOX-mediated ROS burst (Duan et al., 2014) as it happens during root hair growth (Foreman et al., 2003; Orman-Ligeza et al., 2016). Moreover, this process can be reconstituted in vitro by providing exogenous $1 \mathrm{mM} \mathrm{H}_{2} \mathrm{O}_{2}$ (Duan et al., 2014), clearly demonstrating oxidative burst is required for pollen tube rupture. In a broader biological sense, this scenario has reminded us that oxidative burst plays critical roles in cell wall dissolution, as has been evidenced in abscission process in various species (Sakamoto et al., 2008a,b; Yang et al., 2015; Liao et al., 2016). What's more, ROS burst at the site of abscission is most possibly mediated by peroxidase (Poovaiah, 1973; Hall and Sexton, 1974; Henry, 1979; McManus, 1994). A subclass of anatomically distinct cells-smaller size and denser cytoplasm compared to neighboring cells-makes up of the abscission zone, from which cell wall loosening and eventual dissolution will occur under the control of various cell wall remodelers (Roberts et al., 2002; Kim et al., 2015; Merelo et al., 2017; GonzálezCarranza et al., 2018). To be more specific, dissolution is most likely happening in the lamella zone of cell wall (Figure 6) (Agustí et al., 2012; Yamada et al., 2015).

One obvious consequence from abscission is the complete physical cut-off from intercellular transport, although questions remain as to at which stage and in what way the PD permeability is blocked during formation of abscission layer, given the impact of ROS burst and vigorous cell wall remodeling on PD structure and/or permeability.

Interestingly, a recent study on oil palm fruit abscission zone shows that abscission zone is multi-cell layered structure and PD is frequently observed within the layer, but less frequently observed between layers (Roongsattham et al., 2016), suggesting that inter-layer communication via PD is becoming less likely prior to separation. With progression toward abscission, the PD size within layer is enlarged (Roongsattham et al., 2016), fusing membrane vesicles, highly branched PD and its associated cavities in the vicinity of middle lamella are frequently observed (Osborne and Sargent, 1976; Henry, 1979; Bar-Dror et al., 2011; Roongsattham et al., 2016). The physiological function of these branched PD in the abscission layer is yet known, but clues from the presence of branched PD in the trichomeepidermal boundary (Faulkner et al., 2008) where there is only unidirectional transport (Christensen et al., 2009) (Figure 1) and also in the cells undergoing sink-source transition that allows carbon export (Volk et al., 1996; Oparka et al., 1999) suggest that the branched PD in the abscission zone may be involved in the unidirectional transport between the separated tissue and the main body. Alternatively, they are simply results of the vigorous cell wall remodeling, or formed from the fusions of existing simple PD due to ROS burst which would also boost the polarization of membranous system, such as the TNTs formation or stromule, peroxule formation as discussed previously (Figure 6). 


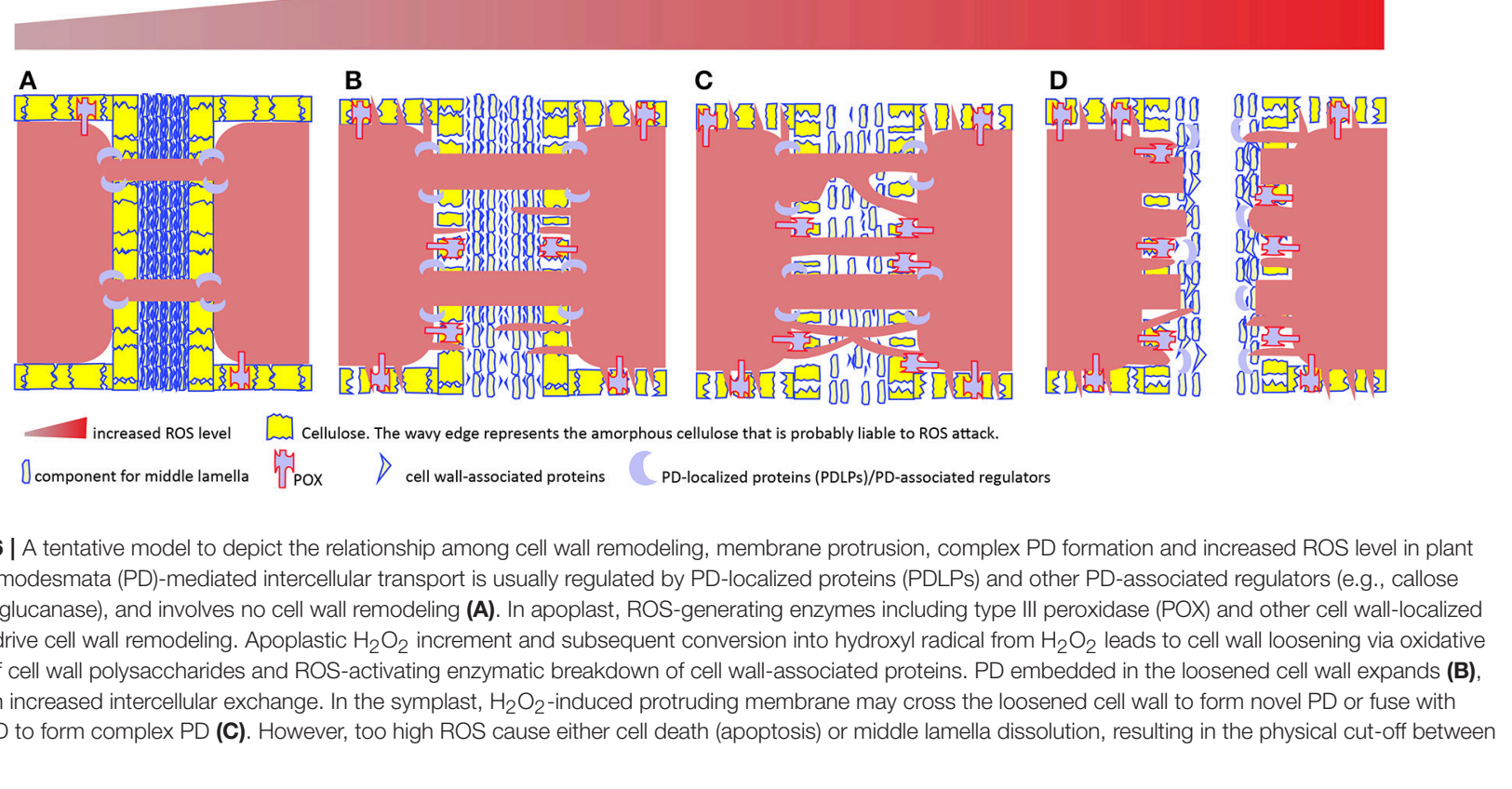

\section{Callose, PD Transport, and Pathogen Penetration}

Decades of research on pathogen-plant interaction have established that cell wall barrier, e.g., cell wall appositions known as papillae, at the site of infection can be formed to constitute a first physical front line against intruder penetration (Aist, 1976), and later that strengthening of this specialized structure is proposed to be driven by ROS burst during infectious attack (Hückelhoven et al., 1999; Grant and Loake, 2000; Torres et al., 2006) as well as iron deposition (Liu et al., 2007). Callose, the most abundant constituent of papillae (Aist, 1976; Schulze-Lefert, 2004; Bellincampi et al., 2014; Voigt, 2014), is considered to assemble quickly at attack site, thereby forming a barrier to resist intruder's penetration. However, this prevailing view does not withstand from two independent genetic studies in which loss of function of GLS5/PMR4 gene coding for a GLUCAN SYNTHASE, indeed, leads to lack of callose deposition at papilla, but paradoxically results in the effective growth cessation of powdery mildew (Jacobs et al., 2003; Nishimura et al., 2003). And more than that, overexpression of the same gene in Arabidopsis, leading to enlarged callose deposits and focal accumulation at sites of attempted fungal penetration, again, jibed with the traditional wisdom (Ellinger et al., 2013).

Therein lies the seemingly irreconcilable contradiction and the role of callose in defending fungal penetration is becoming less conclusive. The structural components of papillae has not been fully understood, therefore, the possibility remains that other factors, beyond the sole function of callose, may account for the discrepancy. By examining the availability of various polysaccharides in barley papillae against Blumeria graminis $f$. sp. hordei, a new study combining immunofluorescence with immunogold-labeling methods reveals that an effective papilla is a multilayered structure, with the inner core consisting of callose and arabinoxylan and the outer layer containing arabinoxylan and cellulose (Chowdhury et al., 2014). Early results showed that inhibition of $\mathrm{H}_{2} \mathrm{O}_{2}$ production by secreted catalase from $B$. graminis $f$. sp. hordei during penetration might interfere with penetration resistance (Zhang et al., 2004), and that inhibition of a POX-mediated ROS burst via direct inactivate of peroxidase activity by fungal effector Pep1 also suppressed penetration resistance (Hemetsberger et al., 2012). These findings allow the proposal of an integrated model in which POX-dependent ROS accumulation together with the multilayered cell wall organization shapes up a resistance barrier to hyphae penetration (Hückelhoven, 2014).

Given the facts that callose homeostasis at the neck region of PD is one of the key mechanisms regulating permeability (Zavaliev et al., 2011; De Storme and Geelen, 2014; Knox and Benitez-Alfonso, 2014) and that PD is exploited by fungal hyphae for spread, at least in the case of rice blast fungus (Kankanala et al., 2007), and also resided with various sensing proteins to detect intruder's presence, thus to trigger its closure (Lee et al., 2011; Faulkner et al., 2013; Caillaud et al., 2014), one may speculate that similar scenario is likely to occur for PD permeability. That is, PD permeability, analogous to hyphae growth through cell wall and/or PD, is regulated by more than callose; cell wall components and how they are organized, and POX-mediated ROS level are acting in concert to determine PD permeability (Figures 2, 6). 


\section{AN EVOLUTIONARY LOGIC TO ROS-REGULATED INTERCELLULAR MOVEMENT}

ROS-controlled biomolecule movement and intercellular/ interorganellar bridge formation, which can facilitate intercellular transfer, in both plants and animals suggest there could be existence of some evolutionary sense that needs to be comprehended. Actually, intercellular communication, as has been proposed from an evolutionary standpoint, is one of the key fundamental traits that are required to be developed for the successful evolution of complex multicellular organisms (Knoll, 2011; Niklas and Newman, 2013). Due to the essential notion in this review expressing that intercellular movement of many types of molecules is controlled by ROS, it would be justifiable to link the role of ROS in intercellular movement to multicellularization. This association is further bolstered by the findings that assigned ROS generation to multicellular organ formation.

Take NOX as an example. A study with Dictyostelium directly defined superoxide as the key signal in its transition from the single to multicellular phase (Bloomfield and Pears, 2003). Without superoxide, the multicellular aggregates simply do not form. The authors further indicate that the source of ROS could result from NOX activity. The ensuing study from independent group demonstrated that insertional disruption in several NOX gene of Dictyostelium indeed gave out defects in the formation of mature fruiting bodies-the multicellular structure (Lardy et al., 2005), genetically consolidating the role of superoxide in multicellular formation.

Actually, NOX enzyme, the ROS generating machinery exists in all multicellular organisms, and is absent from majority of unicellular organisms (Lalucque and Silar, 2003; Hervé et al., 2006; Nguyen et al., 2017). The NOX family has been proposed to be important innovations for the evolution of multicellularity (Blackstone, 2000). Although unicellular fungus such as S. cerevisiae does harbor NOX gene (Rinnerthaler et al., 2012), this does not necessarily argue against the role of ROS-generating machinery in multicellularity as S. cerevisiae can undergo cellular fusion to form a diploid zygote which needs intercellular signaling (Merlini et al., 2013). What's more, several oxidants including $\mathrm{H}_{2} \mathrm{O}_{2}$ can activate mating-responsive genes (Staleva et al., 2004). For complex fungi, NOX deletion does not affect hyphal growth or asexual development, but impairs formation of fruiting body in fungi Aspergillus nidulans and Podospora anserina (Lara-Ortíz et al., 2003; Malagnac et al., 2004), strongly suggesting the presence of ROS-generating machinery is highly correlated to multicellular structure.

As for the existence of NOX family in unicellular algal organisms (Hervé et al., 2006; Anderson et al., 2011; Chang et al., 2016), studies so far have not yet determined the biological role of NOX in unicellular algae. However, it's feasible to speculate that the NOX gene could be, as has been reviewed in the section about stromule formation, used to generate ROS to facilitate interorganelle communication in these algae. Further experiment is needed to clarify this assumption.
NOX is ROS-generating machinery, and its activity is required, at least in fungi, for multicellular formation, but the question remains how the activity is regulated in light of multicellularization. Until recently, an excellent study in $C$. elegans has uncovered a new regulatory mechanism involving tetraspanins (Moribe et al., 2012). Tetraspanins are another well-known multicellularity-associated gene family, which is first innovated in multicellular organisms (Berditchevski, 2001; Huang et al., 2005). Its main role in multicellularization is to facilitate cell adhesion and cell-cell communication (Wang et al., 2012; Charrin et al., 2014). Moribe et al. (2012) showed that null mutation of a tetraspanin gene Tsp-15 causes the worm to be very short and croissant-like phenotype, and leads to embryonic lethality. Genetic screens together with Co-IP and cell-fusion technique identified a concurrent genetic and biochemical pathway in which $\mathrm{H}_{2} \mathrm{O}_{2}$ production is dependent on Tetraspanin (TSP-15)-activated NADPH dual oxidase (BLI3)-maturation factor(DOXA-1) complex (Moribe et al., 2012). The downstream signaling pathway involves peroxidase MLT-7, initiating the extracellular crosslinking process (Thein et al., 2009; Moribe et al., 2012). Although such clear insights are lacking in mammals and plants, emerging work in fungal genetic studies has shown that ROS production and Tetraspanins appear to work concurrently to establish cell-cell contact during fungihost interaction (Moribe and Mekada, 2013). Deletion of either tetraspanin gene PLS1 (Clergeot et al., 2001; Gourgues et al., 2004; Veneault-Fourrey et al., 2005) or NOX genes nox1/nox2 (Egan et al., 2007), or both genes in P. anserina (Lambou et al., 2008) and Botrytis cinerea (Siegmund et al., 2013) renders the fungus "punchless," a condition in which the fungi have defects in penetration. Noteworthily, involvement of tetraspanins and NOX in pathogen-host relationship may not specifically contribute to the pathogenicity, rather hints at an evolutionary strategy to establish interface, thereby enabling transport of nutrients and signaling molecules between fungal and host cells (Bonfante and Genre, 2010). Such is the case with symbiotic interface. NOX-generated ROS in the extracellular matrix is required for fungus Epichloë festucaeis to establish mutualistic association with perennial ryegrass Lolium perenne (Tanaka et al., 2006). Further studies with other symbiotic models could reveal more common grounds of mutual interactions, such as ROS production and its relationship with cell wall remodeling (Lionetti and Métraux, 2014; Martin et al., 2017).

For now, we have learned intercellular transport is the key underpinning to multicellularization and other forms of cellular interaction, e.g., the pathogenic and mutualistic interface, all of whom needs ROS to be involved. Strikingly, geological and archeological records together with phylogenetic analysis have shown that rise and fall of atmospheric oxygen is highly correlated with multicellular emergence and disappearance (Hedges et al., 2004; El Albani et al., 2010, 2014; Schirrmeister et al., 2013). Thus, evolutionary tendency to favor ROS utilization in transport may be incorporated into an evolutionary logic in which oxygen and its associated reactive species contribute to drive the evolution of multicellular life by aiding intercellular transport. 


\section{CONCLUSIONS}

By summarizing the data from across the artificial dye movement, protein movement, gene silencing movement, and intercellular bridge formation we can readily add the role of ROS in facilitating intercellular transport into their signaling repertoire. The ROS effects on membrane protrusions are widely conserved in many different types of animal cells, although diversified signaling networks are present accordingly in different occasions. Key pathways and players involved in membrane protrusions are well-conserved in plants and animals. Superimposed on the plasma membrane, the cell wall in plants poses another challenge to intercellular communication. Remarkably, ROS are still needed for cell wall remodeling. Distinct from NOX that resides on cell membrane and is required for membrane protrusions in animals, the apoplatic player POX that is unique to land plants and located on cell walls (Passardi et al., 2004a,b), is evolved for cell wall remodeling during the evolution of land plants. Convincingly, this role for ROS has actually found its evolutionary logic deeply rooted in the evolution of multicellularity as intercellular communication is one of the key prerequisite for evolving a multicellular organism. Therefore, it is not unintelligible to learn that ROS are widely associated with lots of, if not all of the, physiological processes. If there exists a mechanistic commonality among different physiological processes, then plasmodesmatal path or intercellular bridges could be a candidate hub that converges and dispatches the signaling molecules

\section{REFERENCES}

Abid, M. R., Kachra, Z., Spokes, K. C., and Aird, W. C. (2000). NADPH oxidase activity is required for endothelial cell proliferation and migration. FEBS Lett. 486, 252-256. doi: 10.1016/S0014-5793(00)02305-X

Abounit, S., Bousset, L., Loria, F., Zhu, S., de Chaumont, F., Pieri, L., et al. (2016). Tunneling nanotubes spread fibrillar $\alpha$-synuclein by intercellular trafficking of lysosomes. EMBO J. 35, 2120-2138. doi: 10.15252/embj.201593411

Adamec, L. (2006). Respiration and photosynthesis of bladders and leaves of aquatic utricularia species. Plant Biol. 8, 765-769. doi: 10.1055/s-2006-924540

Adamec, L. (2007). Oxygen concentrations inside the traps of the carnivorous plants Utricularia and Genlisea (Lentibulariaceae). Ann. Bot. 100, 849-856. doi: $10.1093 / \mathrm{aob} / \mathrm{mcm} 182$

Agustí J., Gimeno, J., Merelo, P., Serrano, R., Cercós, M., Conesa, A., et al. (2012). Early gene expression events in the laminar abscission zone of abscissionpromoted citrus leaves after a cycle of water stress/rehydration: involvement of CitbHLH1. J. Exp. Bot. 63, 6079-6091. doi: 10.1093/jxb/ers270

Aist, J. R. (1976). Papillae and related wound plugs of plant cells. Annu. Rev. Phytopathol. 14, 145-163. doi: 10.1146/annurev.py.14.090176.001045

Aller, I., and Meyer, A. J. (2013). The oxidative protein folding machinery in plant cells. Protoplasma 250, 799-816. doi: 10.1007/s00709-012-0463-x

Al-Mohanna, F. A., and Hallett, M. B. (1987). Actin polymerization modifies stimulus-oxidase coupling in rat neutrophils. Biochim. Biophys. Acta 927, 366-371

Anderson, A., Bothwell, J. H., Laohavisit, A., Smith, A. G., and Davies, J. M. (2011). NOX or not? Evidence for algal NADPH oxidases. Trends Plant Sci. 16, 579-581. doi: 10.1016/j.tplants.2011.09.003

Apel, K., and Hirt, H. (2004). Reactive oxygen species: metabolism, oxidative stress, and signal transduction. Annu. Rev. Plant Biol. 55, 373-399. doi: 10.1146/annurev.arplant.55.031903.141701

Apostol, I., Heinstein, P. F., and Low, P. S. (1989). Rapid stimulation of an oxidative burst during elicitation of cultured plant cells: role in defense and signal transduction. Plant Physiol. 90, 109-116 from various developmental and physiological processes for a coordinated response. This would encounter another inevitable question which is how ROS-enabled biomolecule movement is engaging with intercellular gating/selection. So far, we have no candidate answer. With technique advancement in in situ ROS detection, characterization, and resolution of signaling networks, more hidden features are expected to be unearthed in this perplexing but also intriguing area.

\section{AUTHOR CONTRIBUTIONS}

The author confirms being the sole contributor of this work and approved it for publication.

\section{FUNDING}

This work was funded by National Natural Science Foundation of China (31671257) and Hubei Collaborative Innovation Center for Grain Industry (LXT-16-18).

\section{ACKNOWLEDGMENTS}

I would like to thank Dr. Rosemary White, Professor Peter Waterhouse, Dr. Chris Helliwell, Dr. Ming-Bo Wang, Dr. Jean Finnegan, Dr. Danny Llewellyn, and Dr. Liz Dennis for their supports during my postdoctoral training in CSIRO and the University of Sydney. I also thank the reviewers for their valuable suggestion.

Asada, K. (2006). Production and scavenging of reactive oxygen species in chloroplasts and their functions. Plant Physiol. 141, 391-396. doi: $10.1104 / \mathrm{pp} .106 .082040$

Aslan, M., Ryan, T. M., Townes, T. M., Coward, L., Kirk, M. C., Barnes, S., et al. (2003). Nitric oxide-dependent generation of reactive species in sickle cell disease. Actin tyrosine induces defective cytoskeletal polymerization. J. Biol. Chem, 278, 4194-4204. doi: 10.1074/jbc.M208916200

Austefjord, M. W., Gerdes, H.-H., and Wang, X. (2014). Tunneling nanotubes. Commun. Integr. Biol. 7:e27934. doi: 10.4161/cib.27934

Babior, B. M. (2004). NADPH oxidase. Curr. Opin. Immunol. 16, 42-47. doi: 10.1016/j.coi.2003.12.001

Babior, B. M., Kipnes, R. S., and Curnutte, J. T. (1973). Biological defense mechanisms. The production by leukocytes of superoxide, a potential bactericidal agent. J. Clin. Invest. 52, 741-744. doi: 10.1172/jci107236

Bar-Dror, T., Dermastia, M., Kladnik, A., Znidaric, M. T., Novak, M. P., Meir, S. et al. (2011). Programmed cell death occurs asymmetrically during abscission in tomato. Plant Cell 23, 4146-4163. doi: 10.1105/tpc.111.092494

Baxter, A., Mittler, R., and Suzuki, N. (2014). ROS as key players in plant stress signalling. J. Exp. Bot. 65, 1229-1240. doi: 10.1093/jxb/ert375

Bedard, K., and Krause, K. H. (2007). The NOX family of ROS-generating NADPH oxidases: physiology and pathophysiology. Physiol. Rev. 87, 245-313. doi: 10.1152/physrev.00044.2005

Bellincampi, D., Cervone, F., and Lionetti, V. (2014). Plant cell wall dynamics and wall-related susceptibility in plant-pathogen interactions. Front. Plant Sci. 5:228. doi: 10.3389/fpls.2014.00228

Benitez-Alfonso, Y., Cilia, M., San Roman, A., Thomas, C., Maule, A., Hearn, S., et al. (2009). Control of Arabidopsis meristem development by thioredoxindependent regulation of intercellular transport. Proc. Natl. Acad. Sci. U.S.A. 106, 3615-3620. doi: 10.1073/pnas.0808717106

Berditchevski, F. (2001). Complexes of tetraspanins with integrins: more than meets the eye. J. Cell Sci. 114, 4143-4151.

Berglund, G. I., Carlsson, G. H., Smith, A. T., Szöke, H., Henriksen, A., and Hajdu, J. (2002). The catalytic pathway of horseradish 
peroxidase at high resolution. Nature 417, 463-468. doi: 10.1038/ 417463a

Bindschedler, L. V., Dewdney, J., Blee, K. A., Stone, J. M., Asai, T., Plotnikov, J., et al. (2006). Peroxidase-dependent apoplastic oxidative burst in Arabidopsis required for pathogen resistance. Plant J. 47, 851-863. doi: 10.1111/j.1365-313X.2006.02837.x

Bishai, E. A., Sidhu, G. S., Li, W., Dhillon, J., Bohil, A. B., Cheney, R. E., et al. (2013). Myosin-X facilitates Shigella-induced membrane protrusions and cell-to-cell spread. Cell. Microbiol. 15, 353-367. doi: 10.1111/cmi.12051

Blackstone, N. W. (2000). Redox control and the evolution of multicellularity. Bioessays 22, 947-953. doi: 10.1002/1521-1878(200010)22:10<947::aidbies $10>3.0 . c 0 ; 2-\mathrm{w}$

Bloch, D., Pleskot, R., Pejchar, P., Potocký, M., Trpkošová, P., Cwiklik, L., et al. (2016). Exocyst SEC3 and phosphoinositides define sites of exocytosis in pollen tube initiation and growth. Plant Physiol. 172, 980-1002. doi: $10.1104 /$ pp. 16.00690

Bloomfield, G., and Pears, C. (2003). Superoxide signalling required for multicellular development of Dictyostelium. J. Cell Sci. 116, 3387-3397. doi: $10.1242 /$ jcs.00649

Blume, Y. B., Krasylenko, Y. A., Demchuk, O. M., and Yemets, A. I. (2013). Tubulin tyrosine nitration regulates microtubule organization in plant cells. Front. Plant Sci. 4:530. doi: 10.3389/fpls.2013.00530

Bonfante, P., and Genre, A. (2010). Mechanisms underlying beneficial plant-fungus interactions in mycorrhizal symbiosis. Nat. Commun. 1:48. doi: $10.1038 /$ ncomms 1046

Botha, C. E., and van Bel, A. J. (1992). Quantification of symplastic continuity as visualised by plasmodesmograms: diagnostic value for phloem-loading pathways. Planta 187, 359-366. doi: 10.1007/bf00195659

Boyko, V., Ferralli, J., and Heinlein, M. (2000). Cell-to-cell movement of TMV RNA is temperature-dependent and corresponds to the association of movement protein with microtubules. Plant J. 22, 315-325. doi: 10.1046/j.1365-313x.2000.00740.x

Brinkmann, V., Reichard, U., Goosmann, C., Fauler, B., Uhlemann, Y., Weiss, D. S., et al. (2004). Neutrophil extracellular traps kill bacteria. Science 303, 1532-1535. doi: 10.1126/science.1092385

Brunkard, J. O., Runkel, A. M., and Zambryski, P. C. (2015). Chloroplasts extend stromules independently and in response to internal redox signals. Proc. Natl. Acad. Sci. U.S.A. 112, 10044-10049. doi: 10.1073/pnas.1511570112

Buchanan, B. B. (2016). The path to thioredoxin and redox regulation in chloroplasts. Annu. Rev. Plant Biol. 67, 1-24. doi: 10.1146/annurev-arplant-043015-111949

Burch-Smith, T. M., and Zambryski, P. C. (2010). Loss of INCREASED SIZE EXCLUSION LIMIT (ISE)1 or ISE2 increases the formation of secondary plasmodesmata. Curr. Biol. 20, 989-993. doi: 10.1016/j.cub.2010.03.064

Burch-Smith, T. M., and Zambryski, P. C. (2012). Plasmodesmata paradigm shift: regulation from without versus within. Annu. Rev. Plant Biol. 63, 239-260. doi: 10.1146/annurev-arplant-042811-105453

Burch-Smith, T. M., Brunkard, J. O., Choi, Y. G., and Zambryski, P. C. (2011). Organelle-nucleus cross-talk regulates plant intercellular communication via plasmodesmata. Proc. Natl. Acad. Sci. U.S.A. 108, E1451-E1460. doi: $10.1073 /$ pnas. 1117226108

Caillaud, M. C., Wirthmueller, L., Sklenar, J., Findlay, K., Piquerez, S. J. M., Jones, A. M., et al. (2014). The plasmodesmal protein PDLP1 localises to haustoriaassociated membranes during downy mildew infection and regulates callose deposition. PLoS Pathog. 10:e1004496. doi: 10.1371/journal.ppat.1004496

Capook, S. P. (1949). The movement of tobacco mosaic viruses and potato virus $\mathrm{X}$ through tomato plants. Ann. Appl. Biol. 36, 307-319. doi: 10.1111/j.1744-7348.1949.tb06927.x

Caron, E., and Hall, A. (1998). Identification of two distinct mechanisms of phagocytosis controlled by different Rho GTPases. Science 282, 1717-1721.

Chang, Y. L., Li, W. Y., Miao, H., Yang, S. Q., Li, R., Wang, X., et al. (2016). Comprehensive genomic analysis and expression profiling of the NOX gene families under abiotic stresses and hormones in plants. Genome Biol. Evol. 8, 791-810. doi: 10.1093/gbe/evw035

Charrin, S., Jouannet, S., Boucheix, C., and Rubinstein, E. (2014). Tetraspanins at a glance. J. Cell Sci. 127, 3641-3648. doi: 10.1242/jcs.154906

Chen, X. Y., and Kim, J. Y. (2009). Callose synthesis in higher plants. Plant Signal. Behav. 4, 489-492. doi: 10.4161/psb.4.6.8359
Cheung, A. Y., and Wu, H. M. (2008). Structural and signaling networks for the polar cell growth machinery in pollen tubes. Annu. Rev. Plant Biol. 59, 547-572. doi: 10.1146/annurev.arplant.59.032607.092921

Chia, J. X., Efimova, N., and Svitkina, T. M. (2016). Neurite outgrowth is driven by actin polymerization even in the presence of actin polymerization inhibitors. Mol. Biol. Cell 27, 3695-3704. doi: 10.1091/mbc.E16-04-0253

Chianale, F., Rainero, E., Cianflone, C., Bettio, V., Pighini, A., Porporato, P. E., et al. (2010). Diacylglycerol kinase $\alpha$ mediates HGF-induced Rac activation and membrane ruffling by regulating atypical PKC and RhoGDI. Proc. Natl. Acad. Sci.U.S.A. 107, 4182-4187. doi: 10.1073/pnas.0908326107

Choi, H. W., Kim, Y. J., Lee, S. C., Hong, J. K., and Hwang, B. K. (2007). Hydrogen peroxide generation by the pepper extracellular peroxidase $\mathrm{CaPO} 2$ activates local and systemic cell death and defense response to bacterial pathogens. Plant Physiol. 145, 890-904. doi: 10.1104/pp.107.103325

Choi, M. H., Lee, I. K., Kim, G. W., Kim, B. U., Han, Y. H., Yu, D. Y., et al. (2005). Regulation of PDGF signalling and vascular remodelling by peroxiredoxin II. Nature 435, 347-353. doi: 10.1038/nature03587

Chowdhury, J., Henderson, M., Schweizer, P., Burton, R. A., Fincher, G. B. and Little, A. (2014). Differential accumulation of callose, arabinoxylan and cellulose in nonpenetrated versus penetrated papillae on leaves of barley infected with Blumeria graminis f. sp. hordei. New Phytol. 204, 650-660. doi: 10.1111/nph.12974

Christensen, N. M., Faulkner, C., and Oparka, K. (2009). Evidence for unidirectional flow through plasmodesmata. Plant Physiol. 150, 96-104. doi: 10.1104/pp.109.137083

Cleland, R. E., Fujiwara, T., and Lucas, W. J. (1994). Plasmodesmal-mediated cellto-cell transport in wheat roots is modulated by anaerobic stress. Protoplasma 178, 81-85. doi: 10.1007/bf01404123

Clergeot, P. H., Gourgues, M., Cots, J., Laurans, F., Latorse, M.-P., Pépin, R., et al. (2001). PLS1, a gene encoding a tetraspanin-like protein, is required for penetration of rice leaf by the fungal pathogen Magnaporthe grisea. Proc. Natl. Acad. Sci. U.S.A. 98, 6963-6968. doi: 10.1073/pnas. 111132998

Connor, K. M., Hempel, N., Nelson, K. K., Dabiri, G., Gamarra, A., Belarmino, J., et al. (2007). Manganese superoxide dismutase enhances the invasive and migratory activity of tumor cells. Cancer Res. 67, 10260-10267. doi: 10.1158/0008-5472.CAN-07-1204

Crete, P., Leuenberger, S., Iglesias, V. A., Suarez, V., Schob, H., Holtorf, H., et al. (2001). Graft transmission of induced and spontaneous post-transcriptional silencing of chitinase genes. Plant J. 28, 493-501. doi: 10.1046/j.1365-313X.2001.01171.x

Cvetkovska, M., Rampitsch, C., Bykova, N., and Xing, T. (2005). Genomic analysis of MAP kinase cascades inArabidopsis defense responses. Plant Mol. Biol. Rep. 23, 331-343. doi: 10.1007/BF02788882

da Silva, J. S., and Dotti, C. G. (2002). Breaking the neuronal sphere: regulation of the actin cytoskeleton in neuritogenesis. Nat. Rev. Neurosci. 3:694. doi: $10.1038 / n r n 918$

Dalle-Donne, I., Giustarini, D., Rossi, R., Colombo, R., and Milzani, A. (2003). Reversible S-glutathionylation of Cys 374 regulates actin filament formation by inducing structural changes in the actin molecule. Free Radical Biol. Medi. 34, 23-32. doi: 10.1016/S0891-5849(02)01182-6

Dalle-Donne, I., Rossi, R., Giustarini, D., Gagliano, N., Di Simplicio, P., Colombo, R., et al. (2002). Methionine oxidation as a major cause of the functional impairment of oxidized actin. Free Radical Biol. Med. 32, 927-937. doi: 10.1016/S0891-5849(02)00799-2

Daszkowska-Golec, A., and Szarejko, I. (2013). Open or close the gate - stomata action under the control of phytohormones in drought stress conditions. Front. Plant Sci. 4:138. doi: 10.3389/fpls.2013.00138

Daum, G., Medzihradszky, A., Suzaki, T., and Lohmann, J. U. (2014). A mechanistic framework for noncell autonomous stem cell induction in Arabidopsis. Proc. Natl. Acad. Sci. U.S.A. 111, 14619-14624. doi: $10.1073 /$ pnas.140644611

Davies, K. J. (2000). Oxidative stress, antioxidant defenses, and damage removal, repair, and replacement systems. IUBMB Life 50, 279-289. doi: $10.1080 / 713803728$

De Storme, N., and Geelen, D. (2014). Callose homeostasis at plasmodesmata: molecular regulators and developmental relevance. Front. Plant Sci. 5:138. doi: $10.3389 /$ fpls. 2014.00138 
Ding, B., Itaya, A., and Qi, Y. (2003). Symplasmic protein and RNA traffic: regulatory points and regulatory factors. Curr. Opin. Plant Biol. 6, 596-602. doi: 10.1016/j.pbi.2003.09.010

Duan, Q., Kita, D., Johnson, E. A., Aggarwal, M., Gates, L., Wu, H. M., et al. (2014). Reactive oxygen species mediate pollen tube rupture to release sperm for fertilization in Arabidopsis. Nat. Commun. 5:3129. doi: 10.1038/ncomms4129

Duckett, C. M., Oparka, K. J., Prior, D. A. M., Dolan, L., and Roberts, K. (1994). Dye-coupling in the root epidermis of Arabidopsis is progressively reduced during development. Development 120, 3247-3255.

Dunand, C., Crèvecoeur, M., and Penel, C. (2007). Distribution of superoxide and hydrogen peroxide in Arabidopsis root and their influence on root development: possible interaction with peroxidases. New Phytol. 174, 332-341. doi: 10.1111/j.1469-8137.2007.01995.x

Duranteau, J., Chandel, N. S., Kulisz, A., Shao, Z., and Schumacker, P. T. (1998). Intracellular signaling by reactive oxygen species during hypoxia in cardiomyocytes. J. Biol. Chem. 273, 11619-11624.

Egan, M. J., Wang, Z.-Y., Jones, M. A., Smirnoff, N., and Talbot, N. J. (2007). Generation of reactive oxygen species by fungal NADPH oxidases is required for rice blast disease. Proc. Natl. Acad. Sci. U.S.A. 104, 11772-11777. doi: 10.1073/pnas.0700574104

Ehlers, K., and Kollmann, R. (2001). Primary and secondary plasmodesmata: structure, origin, and functioning. Protoplasma 216, 1-30. doi: $10.1007 / \mathrm{BF} 02680127$

Ehlers, K., and van Bel, A. J. (2010). Dynamics of plasmodesmal connectivity in successive interfaces of the cambial zone. Planta 231, 371-385. doi: 10.1007/s00425-009-1046-8

Ehlers, K., and Westerloh, M. G. (2013). "Developmental control of plasmodesmata frequency, structure, and function," in Symplasmic Transport in Vascular Plants, eds K. Sokołowska and P. Sowiński (New York, NY: Springer), 41-82.

El Albani, A., Bengtson, S., Canfield, D. E., Bekker, A., Macchiarelli, R., Mazurier, A., et al. (2010). Large colonial organisms with coordinated growth in oxygenated environments $2.1 \mathrm{Gyr}$ ago. Nature 466, 100-104. doi: 10.1038 /nature09166

El Albani, A., Bengtson, S., Canfield, D. E., Riboulleau, A., Rollion Bard, C., Macchiarelli, R., et al. (2014). The $2.1 \mathrm{Ga}$ old francevillian biota: biogenicity, taphonomy and biodiversity. PLoS ONE 9:e99438. doi: 10.1371/journal.pone.0099438

Ellinger, D., Naumann, M., Falter, C., Zwikowics, C., Jamrow, T., Manisseri, C., et al. (2013). Elevated early callose deposition results in complete penetration resistance to powdery mildew in Arabidopsis. Plant Physiol. 161, 1433-1444. doi: 10.1104/pp.112.211011

Eugenin, E. A., Gaskill, P. J., and Berman, J. W. (2009). Tunneling nanotubes (TNT): a potential mechanism for intercellular HIV trafficking. Commun. Integr. Biol. 2, 243-244. doi: 10.4161/cib.2.3.8165

Farmer, E. E., and Mueller, M. J. (2013). ROS-mediated lipid peroxidation and RES-activated signaling. Аnnu. Rev. Plant Biol. 64, 429-450. doi: 10.1146/annurev-arplant-050312-120132

Faulkner, C., Akman, O. E., Bell, K., Jeffree, C., and Oparka, K. (2008). Peeking into pit fields: a multiple twinning model of secondary plasmodesmata formation in tobacco. Plant Cell 20, 1504-1518. doi: 10.1105/tpc.107.056903

Faulkner, C., Petutschnig, E., Benitez-Alfonso, Y., Beck, M., Robatzek, S., Lipka, V., et al. (2013). LYM2-dependent chitin perception limits molecular flux via plasmodesmata. Proc. Natl. Acad. Sci. U.S.A. 110, 9166-9170. doi: 10.1073/pnas.1203458110

Fedorova, M., Kuleva, N., and Hoffmann, R. (2010). Identification of cysteine, methionine and tryptophan residues of actin oxidized in vivo during oxidative stress. J. Proteome Res. 9, 1598-1609. doi: 10.1021/pr901099e

Fichtenbauer, D., Xu, X. M., Jackson, D., and Kragler, F. (2012). The chaperonin CCT8 facilitates spread of tobamovirus infection. Plant Signal. Behav. 7, 318-321. doi: 10.4161/psb.19152

Finkel, T. (2011). Signal transduction by reactive oxygen species. J. Cell Biol. 194, 7-15. doi: $10.1083 /$ jcb. 201102095

Fitzgibbon, J., Beck, M., Zhou, J., Faulkner, C., Robatzek, S., and Oparka, K. (2013). A developmental framework for complex plasmodesmata formation revealed by large-scale imaging of the Arabidopsis leaf epidermis. Plant Cell 25, 57-70. doi: $10.1105 /$ tpc. 112.105890

Foreman, J., Demidchik, V., Bothwell, J. H., Mylona, P., Miedema, H., Torres, M. A., et al. (2003). Reactive oxygen species produced by NADPH oxidase regulate plant cell growth. Nature 422, 442-446. doi: 10.1038/nature01485
Foyer, C. H., and Noctor, G. (2005). Oxidant and antioxidant signalling in plants: a re-evaluation of the concept of oxidative stress in a physiological context. Plant Cell Environ. 28, 1056-1071. doi: 10.1111/j.1365-3040.2005.01327.x

Fry, S. C. (1998). Oxidative scission of plant cell wall polysaccharides by ascorbateinduced hydroxyl radicals. Biochem. J. 332, 507-515.

Furukawa, Y., Okuyama, S., Amakura, Y., Watanabe, S., Fukata, T., Nakajima, M., et al. (2012). Isolation and characterization of activators of ERK/MAPK from citrus plants. Int. J. Mol. Sci. 13, 1832-1845. doi: 10.3390/ijms13021832

Galkina, S. I., Molotkovsky, J. G., Ullrich, V., and Sud'ina, G. F. (2005). Scanning electron microscopy study of neutrophil membrane tubulovesicular extensions (cytonemes) and their role in anchoring, aggregation and phagocytosis. The effect of nitric oxide. Exp. Cell Res. 304, 620-629. doi: 10.1016/j.yexcr.2004.12.005

Galkina, S. I., Romanova, J. M., Stadnichuk, V. I., Molotkovsky, J. G., Sud'ina, G. F., and Klein, T. (2009). Nitric oxide-induced membrane tubulovesicular extensions (cytonemes) of human neutrophils catch and hold Salmonella enterica serovar Typhimurium at a distance from the cell surface. FEMS Immunol. Med. Microbiol. 56, 162-171. doi: 10.1111/j.1574-695X.2009.00560.x

Gallagher, K. L., Paquette, A. J., Nakajima, K., and Benfey, P. N. (2004). Mechanisms regulating SHORT-ROOT intercellular movement. Curr. Biol. 14, 1847-1851. doi: 10.1016/j.cub.2004.09.081

Gellert, M., Hanschmann, E.-M., Lepka, K., Berndt, C., and Lillig, C. H. (2015). Redox regulation of cytoskeletal dynamics during differentiation and de-differentiation. Biochim. Biophys. Acta 1850, 1575-1587. doi: 10.1016/j.bbagen.2014.10.030

Gerdes, H. H., and Carvalho, R. N. (2008). Intercellular transfer mediated by tunneling nanotubes. Curr. Opin. Cell Biol. 20, 470-475. doi: 10.1016/j.ceb.2008.03.005

Gerdes, H. H., Bukoreshtliev, N. V., and Barroso, J. F. (2007). Tunneling nanotubes: a new route for the exchange of components between animal cells. FEBS Lett. 581, 2194-2201. doi: 10.1016/j.febslet.2007.03.071

Gisel, A., Barella, S., Hempel, F. D., and Zambryski, P. C. (1999). Temporal and spatial regulation of symplastic trafficking during development in Arabidopsis thaliana apices. Development 126, 1879-1889.

González-Carranza, Z. H., Lozoya-Gloria, E., and Roberts, J. A. (2018). Recent developments in abscission: shedding light on the shedding process. Trends Plant Sci. 3, 10-14. doi: 10.1016/s1360-1385(97)01132-1

Goodwin, P. B., Shepherd, V., and Erwee, M. G. (1990). Compartmentation of fluorescent tracers injected into the epidermal cells of Egeria densa leaves. Planta 181, 129-136. doi: 10.1007/bf00202335

Gourgues, M., Brunet-Simon, A., Lebrun, M. H., and Levis, C. (2004). The tetraspanin BcPls1 is required for appressorium-mediated penetration of Botrytis cinerea into host plant leaves. Mol. Microbiol. 51, 619-629. doi: 10.1046/j.1365-2958.2003.03866.x

Gousset, K., Marzo, L., Commere, P. H., and Zurzolo, C. (2013). Myo10 is a key regulator of TNT formation in neuronal cells. J. Cell Sci. 126 (Pt 19), 4424-4435. doi: $10.1242 /$ jcs. 129239

Grant, J. J., and Loake, G. J. (2000). Role of reactive oxygen intermediates and cognate redox signaling in disease resistance. Plant Physiol. 124, 21-30. doi: $10.1104 / p p \cdot 124.1 .21$

Gray, J. C., Hansen, M. R., Shaw, D. J., Graham, K., Dale, R., Smallman, P., et al. (2012). Plastid stromules are induced by stress treatments acting through abscisic acid. Plant J. 69, 387-398. doi: 10.1111/j.1365-313X.2011.04800.x

Gunning, B. E. (2005). Plastid stromules: video microscopy of their outgrowth, retraction, tensioning, anchoring, branching, bridging, and tip-shedding. Protoplasma 225, 33-42. doi: 10.1007/s00709-004-0073-3

Gurke, S., Barroso, J. F., and Gerdes, H. H. (2008). The art of cellular communication: tunneling nanotubes bridge the divide. Histochem. Cell Biol. 129, 539-550. doi: 10.1007/s00418-008-0412-0

Hall, J. L., and Sexton, R. (1974). Fine structure and cytochemistry of the abscission zone cells of phaseolus leaves: II. Localization of peroxidase and acid phosphatase in the separation zone cells. Ann. Bot. 38, 855-858. doi: 10.1093/oxfordjournals.aob.a084876

Halliwell, B., and Gutteridge, J. M. C. (1989). Free Radicals in Biology and Medicine. Oxford: Clarendon Press.

Han, X., Kumar, D., Chen, H., Wu, S., and Kim, J. Y. (2014). Transcription factor-mediated cell-to-cell signalling in plants. J. Exp. Bot. 65, 1737-1749. doi: $10.1093 /$ jxb/ert422

Hanna, S. J., McCoy-Simandle, K., Miskolci, V., Guo, P., Cammer, M., Hodgson, L., et al. (2017). The role of Rho-GTPases and actin polymerization 
during macrophage tunneling nanotube biogenesis. Sci. Rep. 7:8547. doi: 10.1038/s41598-017-08950-7

Hanson, M. R. (2015). Reactive oxygen species signal chloroplasts to extend themselves. Proc. Natl. Acad. Sci. U.S.A. 112, 9799-9800. doi: 10.1073/pnas.1512645112

Harfouche, R., Malak, N. A., Brandes, R. P., Karsan, A., Irani, K., and Hussain, S. N. (2005). Roles of reactive oxygen species in angiopoietin-1/tie-2 receptor signaling. FASEB J. 19, 1728-1730. doi: 10.1096/fj.04-3621fje

Harrison, R. (2002). Structure and function of xanthine oxidoreductase: where are we now? Free Radical Biol. Med. 33, 774-797. doi: 10.1016/S0891-5849(02)00956-5

Hartl, F. U., Bracher, A., and Hayer-Hartl, M. (2011). Molecular chaperones in protein folding and proteostasis. Nature 475, 324-332. doi: 10.1038/nature1 0317

Hase, K., Kimura, S., Takatsu, H., Ohmae, M., Kawano, S., Kitamura, H., et al. (2009). M-Sec promotes membrane nanotube formation by interacting with Ral and the exocyst complex. Nat. Cell Biol. 11, 1427-1432. doi: 10.1038/ ncb1990

Hashimoto, M., Bhuyan, F., Hiyoshi, M., Noyori, O., Nasser, H., Miyazaki, M., et al. (2016). Potential role of the formation of tunneling nanotubes in HIV-1 spread in macrophages. J. Immunol. 196, 1832-1841. doi: 10.4049/jimmunol.1500845

Hassanain, H. H., Sharma, Y. K., Moldovan, L., Khramtsov, V., Berliner, L. J., Duvick, J. P., et al. (2000). Plant rac proteins induce superoxide production in mammalian cells. Biochem. Biophys. Res. Commun. 272, 783-788. doi: $10.1006 / \mathrm{bbrc} .2000 .2791$

Hedges, S. B., Blair, J. E., Venturi, M. L., and Shoe, J. L. (2004). A molecular timescale of eukaryote evolution and the rise of complex multicellular life. $B M C$ Evol. Biol. 4:2. doi: 10.1186/1471-2148-4-2

Helms, K., and Wardlaw, I. F. (1978). Translocation of tobacco mosaic virus and photosynthetic assimilate in Nicotiana glutinosa. Physiol. Plant Pathol. 13, 23-36.

Hemetsberger, C., Herrberger, C., Zechmann, B., Hillmer, M., and Doehlemann, G. (2012). The Ustilago maydis effector Pep1 suppresses plant immunity by inhibition of host peroxidase activity. PLoS Pathog. 8:e1002684. doi: 10.1371/journal.ppat.1002684

Henry, E. W. (1979). Peroxidases in tobacco abscission zone tissue. VI. Ultrastructural localization in plasmodesmata during ethylene-induced abscission. Cytologia 44, 135-152. doi: 10.1508/cytologia.44.135

Hervé C., Tonon, T., Collén, J., Corre, E., and Boyen, C. (2006). NADPH oxidases in Eukaryotes: red algae provide new hints! Curr. Genet. 49, 190-204. doi: $10.1007 / \mathrm{s} 00294-005-0044-\mathrm{z}$

Hille, R., and Nishino, T. (1995). Flavoprotein structure and mechanism. 4. Xanthine oxidase and xanthine dehydrogenase. FASEB J. 9, 995-1003.

Hinshaw, D. B., Sklar, L. A., Bohl, B., Schraufstatter, I. U., Hyslop, P. A., Rossi, M. W., et al. (1986). Cytoskeletal and morphologic impact of cellular oxidant injury. Am. J. Pathol. 123, 454-464.

Ho, J., and Theg, S. M. (2016). The formation of stromules in vitro from chloroplasts isolated from Nicotiana benthamiana. PLoS ONE 11:e0146489. doi: 10.1371/journal.pone.0146489

Holmström, K. M., and Finkel, T. (2014). Cellular mechanisms and physiological consequences of redox-dependent signalling. Nat. Rev. Mol. Cell Biol. 15, 411-421. doi: 10.1038/nrm3801

Horwich, A. L., Fenton, W. A., Chapman, E., and Farr, G. W. (2007). Two families of chaperonin: physiology and mechanism. Annu. Rev. Cell Dev. Biol. 23, 115-145. doi: 10.1146/annurev.cellbio.23.090506.123555

Hsiung, F., Ramirez-Weber, F. A., Iwaki, D. D., and Kornberg, T. B. (2005). Dependence of Drosophila wing imaginal disc cytonemes on Decapentaplegic. Nature 437, 560-563. doi: 10.1038/nature03951

Huang, S., Yuan, S., Dong, M., Su, J., Yu, C., Shen, Y., et al. (2005). The phylogenetic analysis of tetraspanins projects the evolution of cell-cell interactions from unicellular to multicellular organisms. Genomics 86, 674-684. doi: 10.1016/j.ygeno.2005.08.004

Hückelhoven, R. (2014). The effective papilla hypothesis. New Phytol. 204, 438-440. doi: 10.1111/nph.13026

Hückelhoven, R., Fodor, J., Preis, C., and Kogel, K. H. (1999). Hypersensitive cell death and papilla formation in barley attacked by the powdery mildew fungus are associated with hydrogen peroxide but not with salicylic acid accumulation. Plant Physiol. 119, 1251-1260.
Hung, R. J., Pak, C. W., and Terman, J. R. (2011). Direct redox regulation of F-actin assembly and disassembly by Mical. Science 334, 1710-1713. doi: $10.1126 /$ science. 1211956

Hung, R. J., Spaeth, C. S., Yesilyurt, H. G., and Terman, J. R. (2013). SelR reverses Mical-mediated oxidation of actin to regulate F-actin dynamics. Nat. Cell Biol. 15, 1445-1454. doi: $10.1038 / \mathrm{ncb} 2871$

Imlau, A., Truernit, E., and Sauer, N. (1999). Cell-to-cell and long-distance trafficking of the green fluorescent protein in the phloem and symplastic unloading of the protein into sink tissues. Plant Cell 11, 309-322.

Jacobs, A. K., Lipka, V., Burton, R. A., Panstruga, R., Strizhov, N., SchulzeLefert, P., et al. (2003). An arabidopsis callose synthase, GSL5, is required for wound and papillary callose formation. Plant Cell 15, 2503-2513. doi: 10.1105/tpc.016097

Jaipargas, E.-A., Mathur, N., Bou Daher, F., Wasteneys, G. O., and Mathur, J. (2016). High light intensity leads to increased peroxule-mitochondria interactions in plants. Front. Cell. Dev. Biol. 4:6. doi: 10.3389/fcell.2016.00006

Jin, Y., Sui, H. J., Dong, Y., Ding, Q., Qu, W. H., Yu, S. X., et al. (2012). Atorvastatin enhances neurite outgrowth in cortical neurons in vitro via up-regulating the Akt/mTOR and Akt/GSK-3beta signaling pathways. Acta Pharmacol. Sin. 33, 861-872. doi: 10.1038/aps.2012.59

Jyoti, A., Singh, A. K., Dubey, M., Kumar, S., Saluja, R., Keshari, R. S., et al. (2014). Interaction of inducible nitric oxide synthase with rac2 regulates reactive oxygen and nitrogen species generation in the human neutrophil phagosomes: implication in microbial killing. Antioxid. Redox Signal. 20, 417-431. doi: 10.1089/ars.2012.4970

Kalantidis, K., Schumacher, H. T., Alexiadis, T., and Helm, J. M. (2008). RNA silencing movement in plants. Biol. Cell 100, 13-26. doi: 10.1042/bc20070079

Kankanala, P., Czymmek, K., and Valent, B. (2007). Roles for rice membrane dynamics and plasmodesmata during biotrophic invasion by the blast fungus. Plant Cell 19, 706-724. doi: 10.1105/tpc.106.046300

Kasprowicz, A., Szuba, A., Volkmann, D., Baluška, F., and Wojtaszek, P. (2009). Nitric oxide modulates dynamic actin cytoskeleton and vesicle trafficking in a cell type-specific manner in root apices. J. Exp. Bot. 60, 1605-1617. doi: 10.1093/jxb/erp033

Kawakami, S., Watanabe, Y., and Beachy, R. N. (2004). Tobacco mosaic virus infection spreads cell to cell as intact replication complexes. Proc. Natl. Acad. Sci. U.S.A. 101, 6291-6296. doi: 10.1073/pnas.0401221101

Kawano, Y., Kaneko-Kawano, T., and Shimamoto, K. (2014). Rho family GTPase-dependent immunity in plants and animals. Front. Plant Sci. 5:522. doi: 10.3389 /fpls.2014.00522

Kim, I., Hempel, F. D., Sha, K., Pfluger, J., and Zambryski, P. C. (2002). Identification of a developmental transition in plasmodesmatal function during embryogenesis in Arabidopsis thaliana. Development 129, 1261-1272.

Kim, J. Y., Yuan, Z., Cilia, M., Khalfan-Jagani, Z., and Jackson, D. (2002). Intercellular trafficking of a KNOTTED1 green fluorescent protein fusion in the leaf and shoot meristem of Arabidopsis. Proc. Natl. Acad. Sci. U.S.A. 99, 4103-4108. doi: 10.1073/pnas.052484099

Kim, J., Sundaresan, S., Philosoph-Hadas, S., Yang, R., Meir, S., and Tucker, M. L. (2015). Examination of the abscission-associated transcriptomes for soybean, tomato, and Arabidopsis highlights the conserved biosynthesis of an extensible extracellular matrix and boundary layer. Front. Plant Sci. 6:1109. doi: $10.3389 /$ fpls.2015.01109

Kimura, M., Umemoto, Y., and Kawano, T. (2014). Hydrogen peroxideindependent generation of superoxide by plant peroxidase: hypotheses and supportive data employing ferrous ion as a model stimulus. Front. Plant Sci. 5:285. doi: $10.3389 /$ fpls.2014.00285

Kimura, S., Waszczak, C., Hunter, K., and Wrzaczek, M. (2017). Bound by fate: the role of reactive oxygen species in receptor-like kinase signaling. Plant Cell 29, 638-654. doi: $10.1105 /$ tpc. 16.00947

Klebanoff, S. J. (1970). Myeloperoxidase: contribution to the microbicidal activity of intact leukocytes. Science 169, 1095-1097.

Klotz, L. O. (2002). Oxidant-induced signaling: effects of peroxynitrite and singlet oxygen. Biol. Chem. 383, 443-456. doi: 10.1515/bc.2002.047

Knoll, A. H. (2011). The multiple origins of complex multicellularity. Annu. Rev. Earth Planet. Sci. 39, 217-239. doi: 10.1146/annurev.earth.031208.100209

Knox, J. P., and Benitez-Alfonso, Y. (2014). Roles and regulation of plant cell walls surrounding plasmodesmata. Curr. Opin. Plant Biol. 22, 93-100. doi: $10.1016 /$ j.pbi.2014.09.009 
Kobayashi, K., Otegui, M. S., Krishnakumar, S., Mindrinos, M., and Zambryski, P. (2007). INCREASED SIZE EXCLUSION LIMIT 2 encodes a putative DEVH box RNA helicase involved in plasmodesmata function during Arabidopsis embryogenesis. Plant Cell 19, 1885-1897. doi: 10.1105/tpc.106.045666

Kondrikov, D., Fonseca, F. V., Elms, S., Fulton, D., Black, S. M., Block, E. R., et al. (2010). $\beta$-actin association with endothelial nitric-oxide synthase modulates nitric oxide and superoxide generation from the enzyme. J. Biol. Chem. 285, 4319-4327. doi: 10.1074/jbc.M109.063172

Kondrikov, D., Han, H. R., Block, E. R., and Su, Y. (2006). Growth and densitydependent regulation of NO synthase by the actin cytoskeleton in pulmonary artery endothelial cells. Am. J. Physiol. Lung Cell. Mol. Physiol. 290, L41-L50. doi: 10.1152/ajplung.00444.2004

Kroeger, J. H., and Geitmann, A. (2012). Pollen tube growth: Getting a grip on cell biology through modeling. Mech. Res. Commun. 42(Suppl. C), 32-39. doi: 10.1016/j.mechrescom.2011.11.005

Kunieda, T., Shimada, T., Kondo, M., Nishimura, M., Nishitani, K., and HaraNishimura, I. (2013). Spatiotemporal secretion of PEROXIDASE36 is required for seed coat mucilage extrusion in Arabidopsis. Plant Cell 25, 1355-1367. doi: $10.1105 /$ tpc.113.110072

Kwok, E. Y., and Hanson, M. R. (2003). Microfilaments and microtubules control the morphology and movement of non-green plastids and stromules in Nicotiana tabacum. Plant J. 35, 16-26. doi: 10.1046/j.1365-313X.2003.01777.x

Kwok, E. Y., and Hanson, M. R. (2004). In vivo analysis of interactions between GFP-labeled microfilaments and plastid stromules. BMC Plant Biol. 4:2. doi: 10.1186/1471-2229-4-2

Lalucque, H., and Silar, P. (2003). NADPH oxidase: an enzyme for multicellularity? Trends Microbiol. 11, 9-12. doi: 10.1016/S0966-842X(02)00007-0

Lambou, K., Malagnac, F., Barbisan, C., Tharreau, D., Lebrun, M.-H., and Silar, P. (2008). The crucial role of the Pls1 tetraspanin during ascospore germination in podospora anserina provides an example of the convergent evolution of morphogenetic processes in fungal plant pathogens and saprobes. Eukaryot. Cell 7, 1809-1818. doi: 10.1128/ec.00149-08

Landino, L. M., Hasan, R., McGaw, A., Cooley, S., Smith, A. W., Masselam, K., et al. (2002). Peroxynitrite oxidation of tubulin sulfhydryls inhibits microtubule polymerization. Arch. Biochem. Biophys. 398, 213-220. doi: 10.1006/abbi.2001.2729

Landino, L. M., Koumas, M. T., Mason, C. E., and Alston, J. A. (2007). Modification of tubulin cysteines by nitric oxide and nitroxyl donors alters tubulin polymerization activity. Chem. Res. Toxicol. 20, 1693-1700. doi: $10.1021 /$ tx7001492

Lara-Ortíz, T., Riveros-Rosas, H., and Aguirre, J. (2003). Reactive oxygen species generated by microbial NADPH oxidase NoxA regulate sexual development in Aspergillus nidulans. Mol. Microbiol. 50, 1241-1255. doi: 10.1046/j.1365-2958.2003.03800.x

Lardy, B., Bof, M., Aubry, L., Paclet, M. H., Morel, F., Satre, M., et al. (2005). NADPH oxidase homologs are required for normal cell differentiation and morphogenesis in Dictyostelium discoideum. Biochim. Biophys. Acta 1744, 199-212. doi: 10.1016/j.bbamcr.2005.02.004

Lassing, I., Schmitzberger, F., Björnstedt, M., Holmgren, A., Nordlund, P., Schutt, C. E., et al. (2007). Molecular and structural basis for redox regulation of beta-actin. J. Mol. Biol. 370, 331-348. doi: 10.1016/j.jmb.2007.04.056

Lee, C., Miura, K., Liu, X., and Zweier, J. L. (2000). Biphasic regulation of leukocyte superoxide generation by nitric oxide and peroxynitrite. J. Biol. Chem. 275, 38965-38972. doi: 10.1074/jbc.M006341200

Lee, J. Y., Wang, X., Cui, W., Sager, R., Modla, S., Czymmek, K., et al. (2011). A plasmodesmata-localized protein mediates crosstalk between cell-to-cell communication and innate immunity in Arabidopsis. Plant Cell 23, 3353-3373. doi: $10.1105 /$ tpc. 111.087742

Lee, M. Y., San Martin, A., Mehta, P. K., Dikalova, A. E., Garrido, A. M., Datla, S. R., et al. (2009). Mechanisms of vascular smooth muscle NADPH oxidase 1 (Noxl) contribution to injury-induced neointimal formation. Arterioscler. Thromb. Vasc. Biol. 29, 480-487. doi: 10.1161/ATVBAHA.108.181925

Liang, D., Finnegan, E. J., Dennis, E. S., Waterhouse, P. M., and Wang, M. B. (2011). Mobile silencing in plants: what is the signal and what defines the target. Front. Biol. 6:140. doi: 10.1007/s11515-011-1145-3

Liang, D., White, R. G., and Waterhouse, P. M. (2012). Gene silencing in Arabidopsis spreads from the root to the shoot, through a gating barrier, by template-dependent, nonvascular, cell-to-cell movement. Plant Physiol. 159, 984-1000. doi: 10.1104/pp.112.197129
Liang, D., White, R. G., and Waterhouse, P. M. (2014). Mobile gene silencing in Arabidopsis is regulated by hydrogen peroxide. PeerJ 2:e701. doi: 10.7717/peerj.701

Liao, W., Wang, G., Li, Y., Wang, B., Zhang, P., and Peng, M. (2016). Reactive oxygen species regulate leaf pulvinus abscission zone cell separation in response to water-deficit stress in cassava. Sci. Rep. 6:21542. doi: 10.1038/srep 21542

Lim, M. B., Kuiper, J. W., Katchky, A., Goldberg, H., and Glogauer, M. (2011). Rac2 is required for the formation of neutrophil extracellular traps. J. Leukoc. Biol. 90, 771-776. doi: 10.1189/jlb.1010549

Lionetti, V., and Métraux, J.-P. (2014). Plant cell wall in pathogenesis, parasitism and symbiosis. Front. Plant Sci. 5:612. doi: 10.3389/fpls.2014.00612

Liszkay, A., van der Zalm, E., and Schopfer, P. (2004). Production of reactive oxygen intermediates $\left(\mathrm{O}_{2}^{-}, \mathrm{H}_{2} \mathrm{O}_{2}\right.$, and. $\left.\mathrm{OH}\right)$ by maize roots and their role in wall loosening and elongation growth. Plant Physiol. 136, 3114-3123. doi: 10.1104/pp.104.044784

Liu, G., Greenshields, D. L., Sammynaiken, R., Hirji, R. N., Selvaraj, G., and Wei, Y. (2007). Targeted alterations in iron homeostasis underlie plant defense responses. J. Cell Sci. 120 (Pt 4), 596-605. doi: 10.1242/jcs.001362

Liu, J., Yue, P., Artym, V. V., Mueller, S. C., and Guo, W. (2009). The role of the exocyst in matrix metalloproteinase secretion and actin dynamics during tumor cell invadopodia formation. Mol. Biol. Cell 20, 3763-3771. doi: 10.1091/mbc.E08-09-0967

Liu, Y., and He, C. (2017). A review of redox signaling and the control of MAP kinase pathway in plants. Redox Biol. 11(Suppl. C), 192-204. doi: 10.1016/j.redox.2016.12.009

Loesch, A., Belai, A., and Burnstock, G. (1994). An ultrastructural study of $\mathrm{NADPH}$-diaphorase and nitric oxide synthase in the perivascular nerves and vascular endothelium of the rat basilar artery. J. Neurocytol. 23, 49-59.

Long, Y., Scheres, B., and Blilou, I. (2015). The logic of communication: roles for mobile transcription factors in plants. J. Exp. Bot. 66, 1133-1144. doi: $10.1093 / \mathrm{jxb} / \mathrm{eru} 548$

Lou, S. S., Diz-Muñoz, A., Weiner, O. D., Fletcher, D. A., and Theriot, J. A. (2015). Myosin light chain kinase regulates cell polarization independently of membrane tension or Rho kinase. J. Cell Biol. 209, 275-288. doi: $10.1083 /$ jcb. 201409001

Lucas, W. J., and Lee, J. Y. (2004). Plasmodesmata as a supracellular control network in plants. Nat. Rev. Mol. Cell Biol. 5, 712-726. doi: 10.1038/nrm1470

Lucas, W. J., Bouché-Pillon, S., Jackson, D. P., Nguyen, L., Baker, L., Ding, B., et al. (1995). Selective trafficking of KNOTTED1 homeodomain protein and its mRNA through plasmodesmata. Science 270, 1980-1983. doi: 10.1126/science. 270.5244 .1980

Ma, X., Wang, W., Bittner, F., Schmidt, N., Berkey, R., Zhang, L., et al. (2016). Dual and opposing roles of xanthine dehydrogenase in defense-associated reactive oxygen species metabolism in Arabidopsis. Plant Cell 28, 1108-1126. doi: $10.1105 /$ tpc. 15.00880

Malagnac, F., Lalucque, H., Lepère, G., and Silar, P. (2004). Two NADPH oxidase isoforms are required for sexual reproduction and ascospore germination in the filamentous fungus Podospora anserina. Fungal Genet. Biol. 41, 982-997. doi: $10.1016 /$ j.fgb.2004.07.008

Malhotra, J. D., and Kaufman, R. J. (2007). Endoplasmic reticulum stress and oxidative stress: a vicious cycle or a double-edged sword? Antioxid. Redox Signal. 9, 2277-2293. doi: 10.1089/ars.2007.1782

Mangano, S., Juárez, S. P., and Estevez, J. M. (2016). ROS regulation of polar growth in plant cells. Plant Physiol. 171, 1593-1605. doi: 10.1104/pp.16.00191

Martin, F. M., Uroz, S., and Barker, D. G. (2017). Ancestral alliances: plant mutualistic symbioses with fungi and bacteria. Science 356:aad4501. doi: $10.1126 /$ science.aad4501

Marzo, L., Gousset, K., and Zurzolo, C. (2012). Multifaceted roles of tunneling nanotubes in intercellular communication. Front. Physiol. 3:72. doi: $10.3389 /$ fphys.2012.00072

Mathur, J., Mammone, A., and Barton, K. A. (2012). Organelle extensions in plant cells. J. Integr. Plant Biol. 54, 851-867. doi: 10.1111/j.1744-7909.2012.01175.x

McManus, M. T. (1994). Peroxidases in the separation zone during ethylene-induced bean leaf abscission. Phytochemistry 35, 567-572. doi: 10.1016/S0031-9422(00)90562-4

Melnyk, C. W., Molnar, A., and Baulcombe, D. C. (2011). Intercellular and systemic movement of RNA silencing signals. EMBO J. 30, 3553-3563. doi: $10.1038 /$ emboj.2011.274 
Mendoza, M. C., Er, E. E., Zhang, W., Ballif, B. A., Elliott, H. L., Danuser, G., et al. (2011). ERK-MAPK drives lamellipodia protrusion by activating the WAVE2 regulatory complex. Mol. Cell 41, 661-671. doi: 10.1016/j.molcel.2011.02.031

Merelo, P., Agustí J., Arbona, V., Costa, M. L., Estornell, L. H., GómezCadenas, A., et al. (2017). Cell wall remodeling in abscission zone cells during ethylene-promoted fruit abscission in citrus. Front. Plant Sci. 8:126. doi: $10.3389 /$ fpls.2017.00126

Merlini, L., Dudin, O., and Martin, S. G. (2013). Mate and fuse: how yeast cells do it. Open Biol. 3:130008. doi: 10.1098/rsob.130008

Mitchell, T., Lo, A., Logan, M. R., Lacy, P., and Eitzen, G. (2008). Primary granule exocytosis in human neutrophils is regulated by Racdependent actin remodeling. Am. J. Physiol. Cell Physiol. 295, C1354-C1365. doi: $10.1152 /$ ajpcell.00239.2008

Mittler, R., Vanderauwera, S., Suzuki, N., Miller, G., Tognetti, V. B., Vandepoele, K., et al. (2011). ROS signaling: the new wave? Trends Plant Sci. 16, 300-309. doi: 10.1016/j.tplants.2011.03.007

Moldovan, L., Moldovan, N. I., Sohn, R. H., Parikh, S. A., and GoldschmidtClermont, P. J. (2000). Redox changes of cultured endothelial cells and actin dynamics. Circul. Res. 86, 549-557. doi: 10.1161/01.RES.86.5.549

Moribe, H., and Mekada, E. (2013). Co-occurrence of tetraspanin and ROS generators: conservation in protein cross-linking and other developmental processes. Worm 2:e23415. doi: 10.4161/worm.23415

Moribe, H., Konakawa, R., Koga, D., Ushiki, T., Nakamura, K., and Mekada, E. (2012). Tetraspanin is required for generation of reactive oxygen species by the dual oxidase system in Caenorhabditis elegans. PLoS Genet. 8:e1002957. doi: 10.1371/journal.pgen.1002957

Mortimer, D. C. (1965). Translocation of the products of photosynthesis in sugar beet petioles. Can. J. Bot. 43, 269-280. doi: 10.1139/b65-029

Müller, J., Toev, T., Heisters, M., Teller, J., Moore, K. L., Hause, G., et al. (2015). Iron-dependent callose deposition adjusts root meristem maintenance to phosphate availability. Dev. Cell 33, 216-230. doi: 10.1016/j.devcel.2015.02.007

Müller, K., Linkies, A., Vreeburg, R. A., Fry, S. C., Krieger-Liszkay, A., and Leubner-Metzger, G. (2009). In vivo cell wall loosening by hydroxyl radicals during cress seed germination and elongation growth. Plant Physiol. 150, 1855-1865. doi: 10.1104/pp.109.139204

Munnamalai, V., and Suter, D. M. (2009). Reactive oxygen species regulate F-actin dynamics in neuronal growth cones and neurite outgrowth. J. Neurochem. 108, 644-661. doi: 10.1111/j.1471-4159.2008.05787.x

Nagawa, S., Xu, T., and Yang, Z. (2010). RHO GTPase in plants: conservation and invention of regulators and effectors. Small GTPases 1, 78-88. doi: 10.4161/sgtp.1.2.14544

Nakajima, K., Sena, G., Nawy, T., and Benfey, P. N. (2001). Intercellular movement of the putative transcription factor SHR in root patterning. Nature 413, 307-311. doi: $10.1038 / 35095061$

Nambiar, R., McConnell, R. E., and Tyska, M. J. (2010). Myosin motor function: the ins and outs of actin-based membrane protrusions. Cell. Mol. Life Sci. 67, 1239-1254. doi: 10.1007/s00018-009-0254-5

Natesan, S. K., Sullivan, J. A., and Gray, J. C. (2009). Myosin XI is required for actin-associated movement of plastid stromules. Mol. Plant 2, 1262-1272. doi: $10.1093 / \mathrm{mp} / \mathrm{ssp} 078$

Nguyen, T. A., Cissé O. H., Yun Wong, J., Zheng, P., Hewitt, D., Nowrousian, M., et al. (2017). Innovation and constraint leading to complex multicellularity in the Ascomycota. Nat. Commun. 8:14444. doi: 10.1038/ncomms14444

Nikkanen, L., and Rintamäki, E. (2014). Thioredoxin-dependent regulatory networks in chloroplasts under fluctuating light conditions. Philos. Trans. $R$. Soc. Lond. B Biol. Sci. 369:20130224. doi: 10.1098/rstb.2013.0224

Niklas, K. J., and Newman, S. A. (2013). The origins of multicellular organisms. Evol. Dev. 15, 41-52. doi: 10.1111/ede.12013

Nimnual, A. S., Taylor, L. J., and Bar-Sagi, D. (2003). Redox-dependent downregulation of Rho by Rac. Nat. Cell Biol. 5, 236-241. doi: 10.1038/ncb938

Nishimura, M. T., Stein, M., Hou, B. H., Vogel, J. P., Edwards, H., and Somerville, S. C. (2003). Loss of a callose synthase results in salicylic acid-dependent disease resistance. Science 301, 969-972. doi: 10.1126/science.1086716

O’Brien, J. A., Daudi, A., Finch, P., Butt, V. S., Whitelegge, J. P., Souda, P., et al. (2012). A peroxidase-dependent apoplastic oxidative burst in cultured Arabidopsis cells functions in MAMP-elicited defense. Plant Physiol. 158, 2013-2027. doi: 10.1104/pp.111.190140

Onda, Y., and Kawagoe, Y. (2011). Oxidative protein folding: selective pressure for prolamin evolution in rice. Plant Signal. Behav. 6, 1966-1972. doi: $10.4161 /$ psb.6.12.17967
Oparka, K. J., Roberts, A. G., Boevink, P., Santa Cruz, S., Roberts, I., Pradel, K. S., et al. (1999). Simple, but not branched, plasmodesmata allow the nonspecific trafficking of proteins in developing tobacco leaves. Cell 97, 743-754.

Orman-Ligeza, B., Parizot, B., de Rycke, R., Fernandez, A., Himschoot, E., Van Breusegem, F., et al. (2016). RBOH-mediated ROS production facilitates lateral root emergence in Arabidopsis. Development 143, 3328-3339. doi: 10.1242/dev.136465

Osborne, D. J., and Sargent, J. A. (1976). The positional differentiation of ethyleneresponsive cells in rachis abscission zones in leaves of Sambucus nigra and their growth and ultrastructural changes at senescence and separation. Planta 130, 203-210. doi: 10.1007/bf00384421

Otero, S., Helariutta, Y., and Benitez-Alfonso, Y. (2016). Symplastic communication in organ formation and tissue patterning. Curr. Opin. Plant Biol. 29:21-28. doi: 10.1016/j.pbi.2015.10.007

Ozgur, R., Turkan, I., Uzilday, B., and Sekmen, A. H. (2014). Endoplasmic reticulum stress triggers ROS signalling, changes the redox state, and regulates the antioxidant defence of Arabidopsis thaliana. J. Exp. Bot. 65, 1377-1390. doi: $10.1093 / \mathrm{jxb} / \mathrm{eru} 034$

Palauqui, J. C., Elmayan, T., Pollien, J. M., and Vaucheret, H. (1997). Systemic acquired silencing: transgene-specific post-transcriptional silencing is transmitted by grafting from silenced stocks to non-silenced scions. EMBO J. 16, 4738-4745. doi: 10.1093/emboj/16.15.4738

Passardi, F., Longet, D., Penel, C., and Dunand, C. (2004a). The class III peroxidase multigenic family in rice and its evolution in land plants. Phytochemistry 65, 1879-1893. doi: 10.1016/j.phytochem.2004. 06.023

Passardi, F., Penel, C., and Dunand, C. (2004b). Performing the paradoxical: how plant peroxidases modify the cell wall. Trends Plant Sci. 9, 534-540. doi: 10.1016/j.tplants.2004.09.002

Patel, S., Kumar, S., Jyoti, A., Srinag, B. S., Keshari, R. S., Saluja, R., et al. (2010). Nitric oxide donors release extracellular traps from human neutrophils by augmenting free radical generation. Nitric Oxide 22, 226-234. doi: 10.1016/j.niox.2010.01.001

Patel, S., Vemula, J., Konikkat, S., Barthwal, M. K., and Dikshit, M. (2009). Ion channel modulators mediated alterations in NO-induced free radical generation and neutrophil membrane potential. Free Radic. Res. 43, 514-521. doi: $10.1080 / 10715760902887276$

Pérez-Sancho, J., Tilsner, J., Samuels, A. L., Botella, M. A., Bayer, E. M., and Rosado, A. (2016). Stitching organelles: organization and function of specialized membrane contact sites in plants. Trends Cell Biol. 26, 705-717. doi: 10.1016/j.tcb.2016.05.007

Petersen, L. C. (1977). The effect of inhibitors on the oxygen kinetics of cytochrome c oxidase. Biochim. Biophys. Acta 460, 299-307.

Peuke, A. D., Rokitta, M., Zimmermann, U., Schreiber, L., and Haase, A. (2001). Simultaneous measurement of water flow velocity and solute transport in xylem and phloem of adult plants of Ricinus communis over a daily time course by nuclear magnetic resonance spectrometry. Plant Cell Environ. 24, 491-503. doi: 10.1046/j.1365-3040.2001.00704.x

Pieper, G. M., Clarke, G. A., and Gross, G. J. (1994). Stimulatory and inhibitory action of nitric oxide donor agents vs. nitrovasodilators on reactive oxygen production by isolated polymorphonuclear leukocytes. J. Pharmacol. Exp. Ther. 269, 451-456.

Poovaiah, B. W. (1973). Peroxidase activity in the abscission zone of bean leaves during abscission. Plant Physiol. 52, 263-267.

Pospísil, P. (2009). Production of reactive oxygen species by photosystem II. Biochim. Biophys. Acta 1787, 1151-1160. doi: 10.1016/j.bbabio.2009.05.005

Qu, X., Jiang, Y., Chang, M., Liu, X., Zhang, R., and Huang, S. (2015). Organization and regulation of the actin cytoskeleton in the pollen tube. Front. Plant Sci. 5:786. doi: $10.3389 /$ fpls. 2014.00786

Quinn, M. T., Parkos, C. A., and Jesaitis, A. J. (1989). The lateral organization of components of the membrane skeleton and superoxide generation in the plasma membrane of stimulated human neutrophils. Biochim. Biophys. Acta 987, 83-94

Radford, J. E., and White, R. G. (2001). Effects of tissue-preparationinduced callose synthesis on estimates of plasmodesma size exclusion limits. Protoplasma 216, 47-55. doi: 10.1007/BF02680130

Raghu, G., Striker, L., Harlan, J., Gown, A., and Striker, G. (1986). Cytoskeletal changes as an early event in hydrogen peroxide-induced cell injury: a study in A549 cells. Br. J. Exp. Pathol. 67, 105-112. 
Ramírez-Weber, F. A., and Kornberg, T. B. (1999). Cytonemes: cellular processes that project to the principal signaling center in Drosophila imaginal discs. Cell 97, 599-607.

Ranzinger, J., Rustom, A., Heide, D., Morath, C., Schemmer, P., Nawroth, P. P., et al. (2014). The receptor for advanced glycation end-products (RAGE) plays a key role in the formation of nanotubes (NTs) between peritoneal mesothelial cells and in murine kidneys. Cell Tissue Res. 357, 667-679. doi: 10.1007/s00441-014-1904-y

Ray, P. D., Huang, B. W., and Tsuji, Y. (2012). Reactive oxygen species (ROS) homeostasis and redox regulation in cellular signaling. Cell. Signal. 24, 981-990. doi: $10.1016 /$ j.cellsig.2012.01.008

Ren, J., and Guo, W. (2012). ERK1/2 regulate exocytosis through direct phosphorylation of the exocyst component Exo70. Dev. Cell 22, 967-978. doi: 10.1016/j.devcel.2012.03.005

Requena, L., and Bornemann, S. (1999). Barley (Hordeum vulgare) oxalate oxidase is a manganese-containing enzyme. Biochem. J. 343(Pt 1), 185-190.

Rhee, S. G. (2006). Cell signaling. H2O2, a necessary evil for cell signaling. Science 312, 1882-1883. doi:10.1126/science.1130481

Rinne, P. L., and van der Schoot, C. (1998). Symplasmic fields in the tunica of the shoot apical meristem coordinate morphogenetic events. Development 125 , 1477-1485.

Rinnerthaler, M., Büttner, S., Laun, P., Heeren, G., Felder, T. K., Klinger, H., et al. (2012). Ynolp/Aim14p, a NADPH-oxidase ortholog, controls extramitochondrial reactive oxygen species generation, apoptosis, and actin cable formation in yeast. Proc. Natl. Acad. Sci. U.S.A. 109, 8658-8663. doi: 10.1073/pnas.1201629109

Río, L. A., and Puppo, A. (2009). Reactive Oxygen Species in Plant Signaling. Berlin; Heidelberg: Springer.

Roberts, A. G., and Oparka, K. J. (2003). Plasmodesmata and the control of symplastic transport. Plant Cell Environ. 26, 103-124. doi: 10.1046/j.1365-3040.2003.00950.x

Roberts, A. W., Kim, C., Zhen, L., Lowe, J. B., Kapur, R., Petryniak, B., et al. (1999). Deficiency of the hematopoietic cell-specific rho family GTPase Rac2 Is characterized by abnormalities in neutrophil function and host defense. Immunity 10, 183-196.

Roberts, J. A., Elliott, K. A., and Gonzalez-Carranza, Z. H. (2002). Abscission, dehiscence, and other cell separation processes. Annu. Rev. Plant Biol. 53, 131-158. doi: 10.1146/annurev.arplant.53.092701.180236

Rodríguez-Serrano, M., Pazmiño, D. M., Sparkes, I., Rochetti, A., Hawes, C., Romero-Puertas, M. C., et al. (2014). 2,4-Dichlorophenoxyacetic acid promotes S-nitrosylation and oxidation of actin affecting cytoskeleton and peroxisomal dynamics. J. Exp. Bot. 65, 4783-4793. doi: 10.1093/jxb/ eru237

Rodríguez-Serrano, M., Romero-Puertas, M. C., Sanz-Fernández, M., Hu, J., and Sandalio, L. M. (2016). Peroxisomes extend peroxules in a fast response to stress via a reactive oxygen species-mediated induction of the peroxin PEX11a. Plant Physiol. 171, 1665-1674. doi: 10.1104/pp.16.00648

Roelfsema, M. R., and Hedrich, R. (2010). Making sense out of $\mathrm{Ca}^{2+}$ signals: their role in regulating stomatal movements. Plant Cell Environ. 33, 305-321. doi: $10.1111 / j .1365-3040.2009 .02075 . x$

Roongsattham, P., Morcillo, F., Fooyontphanich, K., Jantasuriyarat, C., Tragoonrung, S., Amblard, P., et al. (2016). Cellular and pectin dynamics during abscission zone development and ripe fruit abscission of the monocot oil palm. Front. Plant Sci. 7:540. doi: 10.3389/fpls.2016.00540

Roux, P. P., and Blenis, J. (2004). ERK and p38 MAPK-activated protein kinases: a family of protein kinases with diverse biological functions. Microbiol. Mol. Biol. Rev. 68, 320-344. doi: 10.1128/MMBR.68.2.320-344.2004

Royer-Pokora, B., Kunkel, L. M., Monaco, A. P., Goff, S. C., Newburger, P. E., Baehner, R. L., et al. (1986). Cloning the gene for an inherited human disorderchronic granulomatous disease-on the basis of its chromosomal location. Nature 322, 32-38. doi: 10.1038/322032a0

Rustom, A. (2009). Hen or egg? some thoughts on tunneling nanotubes. Ann. N. Y. Acad. Sci. 1178, 129-136. doi: 10.1111/j.1749-6632.2009.04997.x

Rustom, A. (2016). The missing link: does tunnelling nanotube-based supercellularity provide a new understanding of chronic and lifestyle diseases? Open Biol. 6:160057. doi: 10.1098/rsob.160057

Rustom, A., Saffrich, R., Markovic, I., Walther, P., and Gerdes, H. H. (2004). Nanotubular highways for intercellular organelle transport. Science 303, 1007-1010. doi: 10.1126/science.1093133
Rutkowski, D. T., and Kaufman, R. J. (2007). That which does not kill me makes me stronger: adapting to chronic ER stress. Trends Biochem. Sci. 32, 469-476. doi: $10.1016 /$ j.tibs.2007.09.003

Rutschow, H. L., Baskin, T. I., and Kramer, E. M. (2011). Regulation of solute flux through plasmodesmata in the root meristem. Plant Physiol. 155, 1817-1826. doi: 10.1104/pp.110.168187

Saczko-Brack, D., Warchol, E., Rogez, B., Kröss, M., Heissler, S. M., Sellers, J. R., et al. (2016). Self-organization of actin networks by a monomeric myosin. Proc. Natl. Acad. Sci. 113, E8387-E8395. doi: 10.1073/pnas.1612719113

Sager, R., and Lee, J. Y. (2014). Plasmodesmata in integrated cell signalling: insights from development and environmental signals and stresses. J. Exp. Bot. 65, 6337-6358. doi: 10.1093/jxb/eru365

Sagi, M., and Fluhr, R. (2006). Production of reactive oxygen species by plant NADPH oxidases. Plant Physiol. 141, 336-340. doi: 10.1104/pp.106.078089

Sakai, J., Li, J., Subramanian, K. K., Mondal, S., Bajrami, B., Hattori, H., et al. (2012). Reactive oxygen species (ROS)-induced actin glutathionylation controls actin dynamics in neutrophils. Immunity 37, 1037-1049. doi: 10.1016/j.immuni.2012.08.017

Sakamoto, M., Munemura, I., Tomita, R., and Kobayashi, K. (2008a). Involvement of hydrogen peroxide in leaf abscission signaling, revealed by analysis with an in vitro abscission system in Capsicum plants. Plant J. 56, 13-27. doi: 10.1111/j.1365-313X.2008.03577.x

Sakamoto, M., Munemura, I., Tomita, R., and Kobayashi, K. (2008b). Reactive oxygen species in leaf abscission signaling. Plant Signal. Behav. 3, 1014-1015. doi: $10.4161 / p s b .6737$

Santos, C. X., Tanaka, L. Y., Wosniak, J., and Laurindo, F. R. (2009). Mechanisms and implications of reactive oxygen species generation during the unfolded protein response: roles of endoplasmic reticulum oxidoreductases, mitochondrial electron transport, and NADPH oxidase. Antioxid. Redox Signal. 11, 2409-2427. doi: 10.1089/ARS.2009.2625

Sarbassov, D. D., Ali, S. M., Kim, D.-H., Guertin, D. A., Latek, R. R., ErdjumentBromage, H., et al. (2004). Rictor, a novel binding partner of mTOR, defines a rapamycin-insensitive and raptor-independent pathway that regulates the cytoskeleton. Curr. Biol. 14, 1296-1302. doi: 10.1016/j.cub.2004.06.054

Sarina, Y. Y., Nakano, O., Hashimoto, T., Kimura, K., Asakawa, Y., Zhong, M., et al. (2013). Induction of neurite outgrowth in PC12 cells by artemisinin through activation of ERK and p38 MAPK signaling pathways. Brain Res. 1490, 61-71. doi: 10.1016/j.brainres.2012.10.059

Sattarzadeh, A., Krahmer, J., Germain, A. D., and Hanson, M. R. (2009). A myosin $\mathrm{XI}$ tail domain homologous to the yeast myosin vacuole-binding domain interacts with plastids and stromules in Nicotiana benthamiana. Mol. Plant 2, 1351-1358. doi: 10.1093/mp/ssp094

Scandalios, J. G. (1997). Oxidative Stress and the Molecular Biology of Antioxidant Defenses. Cold Spring Harbor, NY: Cold Spring Harbor Laboratory Press.

Schattat, M., Barton, K., Baudisch, B., Klösgen, R. B., and Mathur, J. (2011). Plastid stromule branching coincides with contiguous endoplasmic reticulum dynamics. Plant Physiol. 155, 1667-1677. doi: 10.1104/pp.110.170480

Schirrmeister, B. E., de Vos, J. M., Antonelli, A., and Bagheri, H. C. (2013). Evolution of multicellularity coincided with increased diversification of cyanobacteria and the Great Oxidation Event. Proc. Natl. Acad. Sci. U.S.A. 110, 1791-1796. doi: 10.1073/pnas.1209927110

Schlereth, A., Möller, B., Liu, W., Kientz, M., Flipse, J., Rademacher, E. H., et al. (2010). MONOPTEROS controls embryonic root initiation by regulating a mobile transcription factor. Nature 464, 913-916. doi: 10.1038/nature08836

Schmidt, R., Kunkowska, A. B., and Schippers, J. H. (2016). Role of reactive oxygen species during cell expansion in leaves. Plant Physiol. 172, 2098-2106. doi: 10.1104/pp.16.00426

Schopfer, P. (2001). Hydroxyl radical-induced cell-wall loosening in vitro and in vivo: implications for the control of elongation growth. Plant J. 28, 679-688. doi: 10.1046/j.1365-313x.2001.01187.x

Schröder, K., Helmcke, I., Palfi, K., Krause, K. H., Busse, R., and Brandes, R. P. (2007). Nox1 mediates basic fibroblast growth factor-induced migration of vascular smooth muscle cells. Arterioscler. Thromb. Vasc. Biol. 27, 1736-1743. doi: 10.1161/ATVBAHA.107.142117

Schulze-Lefert, P. (2004). Knocking on the heaven's wall: pathogenesis of and resistance to biotrophic fungi at the cell wall. Curr. Opin. Plant Biol. 7, 377-383. doi: $10.1016 /$ j.pbi.2004.05.004

Schwarzländer, M., Fricker, M. D., and Sweetlove, L. J. (2009). Monitoring the in vivo redox state of plant mitochondria: effect of respiratory inhibitors, abiotic 
stress and assessment of recovery from oxidative challenge. Biochim. Biophys. Acta 1787, 468-475. doi: 10.1016/j.bbabio.2009.01.020

Schweikert, C., Liszkay, A., and Schopfer, P. (2000). Scission of polysaccharides by peroxidase-generated hydroxyl radicals. Phytochemistry 53, 565-570. doi: 10.1016/S0031-9422(99)00586-5

Scott, I., Sparkes, I. A., and Logan, D. C. (2007). The missing link: inter-organellar connections in mitochondria and peroxisomes? Trends Plant Sci. 12, 380-381. doi: 10.1016/j.tplants.2007.08.010

Serrato, A. J., Fernández-Trijueque, J., Barajas-López, J. D., Chueca, A., and Sahrawy, M. (2013). Plastid thioredoxins: a "one-for-all" redox-signaling system in plants. Front. Plant Sci. 4:463. doi: 10.3389/fpls.2013.00463

Sessions, A., and Yanofsky, M. (2001). "Positional information in plant development," in Handbook of Plant Science, Vol. 1. ELS, ed K. Roberts (Chichester: John Wiley \& Sons, Ltd), 448-452.

Sewelam, N., Kazan, K., and Schenk, P. M. (2016). Global plant stress signaling: reactive oxygen species at the cross-road. Front. Plant Sci. 7:187. doi: $10.3389 /$ fpls.2016.00187

Sharma, P., Jha, A. B., Dubey, R. S., and Pessarakli, M. (2012). Reactive oxygen species, oxidative damage, and antioxidative defense mechanism in plants under stressful conditions. J. Bot. 2012:26. doi: 10.1155/2012/217037

Shaul, Y. D., and Seger, R. (2007). The MEK/ERK cascade: from signaling specificity to diverse functions. Biochim. Biophys. Acta 1773, 1213-1226. doi: 10.1016/j.bbamcr.2006.10.005

Shimazaki, K., Doi, M., Assmann, S. M., and Kinoshita, T. (2007). Light regulation of stomatal movement. Annu. Rev. Plant Biol. 58, 219-247. doi: 10.1146/annurev.arplant.57.032905.105434

Siegmund, U., Heller, J., van Kann, J. A. L., and Tudzynski, P. (2013). The NADPH oxidase complexes in botrytis cinerea: evidence for a close association with the ER and the tetraspanin Pls1. PLoS ONE 8:e55879. doi: 10.1371/journal.pone.0055879

Sinclair, A. M., Trobacher, C. P., Mathur, N., Greenwood, J. S., and Mathur, J. (2009). Peroxule extension over ER-defined paths constitutes a rapid subcellular response to hydroxyl stress. Plant J. 59, 231-242. doi: 10.1111/j.1365-313X.2009.03863.x

Smith, L. M., Pontes, O., Searle, I., Yelina, N., Yousafzai, F. K., Herr, A. J., et al. (2007). An SNF2 protein associated with nuclear RNA silencing and the spread of a silencing signal between cells in Arabidopsis. Plant Cell 19, 1507-1521. doi: $10.1105 /$ tpc. 107.051540

Song, Y., Miao, Y., and Song, C. P. (2014). Behind the scenes: the roles of reactive oxygen species in guard cells. New Phytol. 201, 1121-1140. doi: $10.1111 /$ nph. 12565

Stahl, Y., and Simon, R. (2013). Gated communities: apoplastic and symplastic signals converge at plasmodesmata to control cell fates. J. Exp. Bot. 64, 5237-5241. doi: $10.1093 / \mathrm{jxb} / \mathrm{ert} 245$

Staleva, L., Hall, A., and Orlow, S. J. (2004). Oxidative stress activates FUS1 and RLM1 Transcription in the yeast Saccharomyces cerevisiae in an oxidant-dependent manner. Mol. Biol. Cell 15, 5574-5582. doi: 10.1091/mbc.E04-02-0142

Stojkov, D., Amini, P., Oberson, K., Sokollik, C., Duppenthaler, A., Simon, H. U., et al. (2017). ROS and glutathionylation balance cytoskeletal dynamics in neutrophil extracellular trap formation. J. Cell Biol. 216, 4073-4090. doi: $10.1083 /$ jcb. 201611168

Stonebloom, S., Brunkard, J. O., Cheung, A. C., Jiang, K., Feldman, L., and Zambryski, P. (2012). Redox states of plastids and mitochondria differentially regulate intercellular transport via plasmodesmata. Plant Physiol. 158, 190-199. doi: 10.1104/pp.111.186130

Stonebloom, S., Burch-Smith, T., Kim, I., Meinke, D., Mindrinos, M., and Zambryski, P. (2009). Loss of the plant DEAD-box protein ISE1 leads to defective mitochondria and increased cell-to-cell transport via plasmodesmata. Proc. Natl. Acad. Sci. U.S.A. 106, 17229-17234. doi: 10.1073/pnas.0909229106

$\mathrm{Su}$, Y., Edwards-Bennett, S., Bubb, M. R., and Block, E. R. (2003). Regulation of endothelial nitric oxide synthase by the actin cytoskeleton. Am. J. Physiol. Cell Physiol. 284, C1542-C1549. doi: 10.1152/ajpcell.00248.2002

$\mathrm{Su}$, Y., Kondrikov, D., and Block, E. R. (2005). Cytoskeletal regulation of nitric oxide synthase. Cell Biochem. Biophys. 43, 439-449. doi: 10.1385/cbb:43:3:439

Sugihara, K., Asano, S., Tanaka, K., Iwamatsu, A., Okawa, K., and Ohta, Y. (2002). The exocyst complex binds the small GTPase RalA to mediate filopodia formation. Nat. Cell Biol. 4, 73-78. doi: 10.1038/ncb720
Sundaresan, M., Yu, Z. X., Ferrans, V. J., Irani, K., and Finkel, T. (1995). Requirement for generation of $\mathrm{H}_{2} \mathrm{O}_{2}$ for platelet-derived growth factor signal transduction. Science 270, 296-299. doi: 10.1126/science.270.5234.296

Suzuki, N., Miller, G., Morales, J., Shulaev, V., Torres, M. A., and Mittler, R. (2011). Respiratory burst oxidases: the engines of ROS signaling. Curr. Opin. Plant Biol. 14, 691-699. doi: 10.1016/j.pbi.2011.07.014

Tahinci, E., and Symes, K. (2003). Distinct functions of Rho and Rac are required for convergent extension during Xenopus gastrulation. Dev. Biol. 259, 318-335. doi: 10.1016/S0012-1606(03)00206-9

Tanaka, A., Christensen, M. J., Takemoto, D., Park, P., and Scott, B. (2006). Reactive oxygen species play a role in regulating a fungus-perennial ryegrass mutualistic interaction. Plant Cell 18, 1052-1066. doi: 10.1105/tpc.105.039263

Tanimura, S., and Takeda, K. (2017). ERK signalling as a regulator of cell motility. J. Biochem. 162, 145-154. doi: 10.1093/jb/mvx048

Tanimura, S., Hashizume, J., Arichika, N., Watanabe, K., Ohyama, K., Takeda, K., et al. (2016). ERK signaling promotes cell motility by inducing the localization of myosin 1E to lamellipodial tips. J. Cell Biol. 214, 475-489. doi: $10.1083 /$ jcb. 201503123

Teahan, C., Rowe, P., Parker, P., Totty, N., and Segal, A. W. (1987). The X-linked chronic granulomatous disease gene codes for the beta-chain of cytochrome b-245. Nature 327, 720-721. doi: 10.1038/327720a0

Tedeschi, G., Cappelletti, G., Negri, A., Pagliato, L., Maggioni, M. G., Maci, R., et al. (2005). Characterization of nitroproteome in neuron-like PC12 cells differentiated with nerve growth factor: identification of two nitration sites in alpha-tubulin. Proteomics 5, 2422-2432. doi: 10.1002/pmic.200401208

Thein, M. C., Winter, A. D., Stepek, G., McCormack, G., Stapleton, G., Johnstone, I. L., et al. (2009). Combined extracellular matrix cross-linking activity of the peroxidase MLT-7 and the dual oxidase BLI- 3 is critical for postembryonic viability in Caenorhabditis elegans. J. Biol. Chem. 284, 17549-17563. doi: 10.1074/jbc.M900831200

Thom, S. R., Bhopale, V. M., Mancini, D. J., and Milovanova, T. N. (2008). Actin S-nitrosylation inhibits neutrophil beta2 integrin function. J. Biol. Chem. 283, 10822-10834. doi: 10.1074/jbc.M709200200

Torres, M. A., Dangl, J. L., and Jones, J. D. G. (2002). Arabidopsis gp91phox homologues AtrbohD and AtrbohF are required for accumulation of reactive oxygen intermediates in the plant defense response. Proc. Natl. Acad. Sci. U.S.A. 99, 517-522. doi: 10.1073/pnas.012452499

Torres, M. A., Jones, J. D. G., and Dangl, J. L. (2006). Reactive Oxygen Species Signaling in Response to Pathogens. Plant Physiol. 141, 373-378. doi: 10.1104/pp.106.079467

Tsukagoshi, H., Busch, W., and Benfey, P. N. (2010). Transcriptional regulation of ROS controls transition from proliferation to differentiation in the root. Cell 143, 606-616. doi: 10.1016/j.cell.2010.10.020

$\mathrm{Tu}$, B. P., and Weissman, J. S. (2004). Oxidative protein folding in eukaryotes: mechanisms and consequences. J. Cell Biol. 164, 341-346. doi: $10.1083 /$ jcb. 200311055

Tucker, E. B. (1993). Azide treatment enhances cell-to-cell diffusion in staminal hairs ofSetcreasea purpurea. Protoplasma 174, 45-49. doi: 10.1007/bf01404041

Turrens, J. F. (2003). Mitochondrial formation of reactive oxygen species. J. Physiol. 552, 335-344. doi: 10.1111/j.1469-7793.2003.00335.x

van der Schoot, C., and van Bel, A. J. (1990). Mapping membrane potential differences and dye-coupling in internodal tissues of tomato (Solanum lycopersicum L.). Planta 182, 9-21. doi: 10.1007/bf00239977

van Kesteren, W. J., van der Schoot, C., and van Bel, A. J. (1988). Symplastic transfer of fluorescent dyes from mesophyll to sieve tube in stripped leaf tissue and partly isolated minor veins of Commelina benghalensis. Plant Physiol. 88, 667-670.

Van Norman, J. M., Breakfield, N. W., and Benfey, P. N. (2011). Intercellular communication during plant development. Plant Cell 23, 855-864. doi: $10.1105 /$ tpc. 111.082982

Vatén, A., Dettmer, J., Wu, S., Stierhof, Y. D., Miyashima, S., Yadav, S. R., et al. (2011). Callose biosynthesis regulates symplastic trafficking during root development. Dev. Cell 21, 1144-1155. doi: 10.1016/j.devcel.2011.10.006

Veneault-Fourrey, C., Parisot, D., Gourgues, M., Laugé, R., Lebrun, M. H., and Langin, T. (2005). The tetraspanin gene ClPLS1 is essential for appressorium-mediated penetration of the fungal pathogen Colletotrichum lindemuthianum. Fungal Genet. Biol. 42, 306-318. doi: 10.1016/j.fgb.2005.01.009 
Victoria, G. S., and Zurzolo, C. (2017). The spread of prion-like proteins by lysosomes and tunneling nanotubes: implications for neurodegenerative diseases. J. Cell Biol. 216, 2633-2644. doi: 10.1083/jcb.201701047

Vieira Dos Santos, C., and Rey, P. (2006). Plant thioredoxins are key actors in the oxidative stress response. Trends Plant Sci. 11, 329-334. doi: $10.1016 /$ j.tplants.2006.05.005

Voigt, C. A. (2014). Callose-mediated resistance to pathogenic intruders in plant defense-related papillae. Front. Plant Sci. 5:168. doi: 10.3389/fpls.2014.00168

Voinnet, O., Vain, P., Angell, S., and Baulcombe, D. C. (1998). Systemic spread of sequence-specific transgene RNA degradation in plants is initiated by localized introduction of ectopic promoterless DNA. Cell 95, 177-187. doi: 10.1016/S0092-8674(00)81749-3

Volk, G. M., Turgeon, R., and Beebe, D. U. (1996). Secondary plasmodesmata formation in the minor-vein phloem of Cucumis melo L. and Cucurbita pepo L. Planta 199, 425-432. doi: 10.1007/bf00195735

Wang, F., Vandepoele, K., and Van Lijsebettens, M. (2012). Tetraspanin genes in plants. Plant Sci. 190, 9-15. doi: 10.1016/j.plantsci.2012.03.005

Wang, N., and Fisher, D. B. (1994). The use of fluorescent tracers to characterize the post-phloem transport pathway in maternal tissues of developing wheat grains. Plant Physiol. 104, 17-27.

Wang, X., Ling, S., Zhao, D., Sun, Q., Li, Q., Wu, F., et al. (2010). Redox regulation of actin by thioredoxin- 1 is mediated by the interaction of the proteins via cysteine 62. Antioxid. Redox Signal. 13, 565-573. doi: 10.1089/ars.2009.2833

Wang, Y., Cui, J., Sun, X., and Zhang, Y. (2011). Tunneling-nanotube development in astrocytes depends on p53 activation. Cell Death Differ. 18, 732-742. doi: $10.1038 /$ cdd.2010.147

Wang, Y.-J., Wei, X.-Y., Jing, X.-Q., Chang, Y.-L., Hu, C.-H., Wang, X., et al. (2016). The fundamental role of NOX family proteins in plant immunity and their regulation. Int. J. Mol. Sci. 17:805. doi: 10.3390/ijms17060805

Wilson, C., and González-Billault, C. (2015). Regulation of cytoskeletal dynamics by redox signaling and oxidative stress: implications for neuronal development and trafficking. Front. Cell. Neurosci. 9:381. doi: 10.3389/fncel.2015.00381

Wilson, C., Terman, J. R., González-Billault, C., and Ahmed, G. (2016). Actin filaments-A target for redox regulation. Cytoskeleton 73, 577-595. doi: $10.1002 / \mathrm{cm} .21315$

Winans, A. M., Collins, S. R., and Meyer, T. (2016). Waves of actin and microtubule polymerization drive microtubule-based transport and neurite growth before single axon formation. Elife 5:e12387. doi: 10.7554/eLife.12387

Windt, C. W., Vergeldt, F. J., de Jager, P. A., and van As, H. (2006). MRI of long-distance water transport: a comparison of the phloem and xylem flow characteristics and dynamics in poplar, castor bean, tomato and tobacco. Plant Cell Environ. 29, 1715-1729. doi: 10.1111/j.1365-3040.2006.01544.x

Winston, W. M., Molodowitch, C., and Hunter, C. P. (2002). Systemic RNAi in C. elegans requires the putative transmembrane protein SID-1. Science 295, 2456-2459. doi: 10.1126/science.1068836

Wu, S., and Gallagher, K. L. (2012). Transcription factors on the move. Curr. Opin. Plant Biol. 15, 645-651. doi:10.1016/j.pbi.2012.09.010

Wu, S., O'Lexy, R., Xu, M., Sang, Y., Chen, X., Yu, Q., et al. (2016). Symplastic signaling instructs cell division, cell expansion, and cell polarity in the ground tissue of Arabidopsis thaliana roots. Proc. Natl. Acad. Sci. U.S.A. 113, 11621-11626. doi: 10.1073/pnas.1610358113

Xu, M., Cho, E., Burch-Smith, T. M., and Zambryski, P. C. (2012). Plasmodesmata formation and cell-to-cell transport are reduced in decreased size exclusion limit 1 during embryogenesis in Arabidopsis. Proc. Natl. Acad. Sci. U.S.A. 109, 5098-5103. doi: 10.1073/pnas.1202919109

Xu, Q., Huff, L. P., Fujii, M., and Griendling, K. K. (2017). Redox regulation of the actin cytoskeleton and its role in the vascular system. Free Radic. Biol. Med. 109(Suppl. C), 84-107. doi: 10.1016/j.freeradbiomed.2017.03.004

Xu, X. M., Wang, J., Xuan, Z., Goldshmidt, A., Borrill, P. G., Hariharan, N., et al. (2011). Chaperonins facilitate KNOTTED1 cell-to-cell trafficking and stem cell function. Science 333, 1141-1144. doi: 10.1126/science. 1205727

Xu, Y., Li, N., Xiang, R., and Sun, P. (2014). Emerging roles of the p38 MAPK and $\mathrm{PI} 3 \mathrm{~K} / \mathrm{AKT} / \mathrm{mTOR}$ pathways in oncogene-induced senescence. Trends Biochem. Sci. 39, 268-276. doi: 10.1016/j.tibs.2014.04.004

Yadav, R. K., Perales, M., Gruel, J., Girke, T., Jönsson, H., and Reddy, G. V. (2011). WUSCHEL protein movement mediates stem cell homeostasis in the Arabidopsis shoot apex. Genes Dev. 25, 2025-2030. doi: 10.1101/gad.17258511

Yamada, Y., Koibuchi, M., Miyamoto, K., Ueda, J., and Uheda, E. (2015). Breakdown of middle lamella pectin by $\bullet \mathrm{OH}$ during rapid abscission in Azolla. Plant Cell Environ. 38, 1555-1564. doi: 10.1111/pce.12505
Yanagisawa, M., Zhang, C., and Szymanski, D. B. (2013). ARP2/3-dependent growth in the plant kingdom: SCARs for life. Front. Plant Sci. 4:166. doi: $10.3389 /$ fpls.2013.00166

Yang, Z., Zhong, X., Fan, Y., Wang, H., Li, J., and Huang, X. (2015). Burst of reactive oxygen species in pedicel-mediated fruit abscission after carbohydrate supply was cut off in longan (Dimocarpus longan). Front. Plant Sci. 6:360. doi: 10.3389 /fpls.2015.00360

Yao, L.-L., Pei, B.-L., Zhou, Q., and Li, Y.-Z. (2012). NO serves as a signaling intermediate downstream of $\mathrm{H}(2) \mathrm{O}(2)$ to modulate dynamic microtubule cytoskeleton during responses to VD-toxins in Arabidopsis. Plant Signal. Behav. 7, 174-177. doi: 10.4161/psb.18768

Yemets, A. I., Krasylenko, Y. A., Lytvyn, D. I., Sheremet, Y. A., and Blume, Y. B. (2011). Nitric oxide signalling via cytoskeleton in plants. Plant Sci. 181, 545-554. doi: 10.1016/j.plantsci.2011.04.017

Yochelis, A., Ebrahim, S., Millis, B., Cui, R., Kachar, B., Naoz, M., et al. (2015). Self-organization of waves and pulse trains by molecular motors in cellular protrusions. Sci. Rep. 5:13521. doi: 10.1038/srep13521

Yoshikawa, S., Shinzawa-Itoh, K., Nakashima, R., Yaono, R., Yamashita, E., Inoue, N., et al. (1998). Redox-coupled crystal structural changes in bovine heart cytochrome c oxidase. Science 280, 1723-1729. doi: $10.1126 /$ science. 280.5370 .1723

Yu, Q., Tian, H., Yue, K., Liu, J., Zhang, B., Li, X., et al. (2016). A P-loop NTPase regulates quiescent center cell division and distal stem cell identity through the regulation of ROS homeostasis in Arabidopsis root. PLoS Genet. 12:e1006175. doi: 10.1371/journal.pgen.1006175

Zarepour, M., Kaspari, K., Stagge, S., Rethmeier, R., Mendel, R. R., and Bittner, F. (2010). Xanthine dehydrogenase AtXDH1 from Arabidopsis thaliana is a potent producer of superoxide anions via its NADH oxidase activity. Plant Mol. Biol. 72, 301-310. doi: 10.1007/s11103-009-9570-2

Zavaliev, R., Ueki, S., Epel, B. L., and Citovsky, V. (2011). Biology of callose (beta-1,3-glucan) turnover at plasmodesmata. Protoplasma 248, 117-130. doi: 10.1007/s00709-010-0247-0

Zhang, H. H., Wang, W., Feng, L., Yang, Y., Zheng, J., Huang, L., et al. (2015). S-nitrosylation of Cofilin-1 serves as a novel pathway for VEGF-stimulated endothelial cell migration. J. Cell. Physiol. 230, 406-417. doi: 10.1002/jcp.24724

Zhang, L., and Zhang, Y. (2015). Tunneling nanotubes between rat primary astrocytes and C6 glioma cells alter proliferation potential of glioma cells. Neurosci. Bull. 31, 371-378. doi: 10.1007/s12264-014-1522-4

Zhang, Y., Liu, C. M., Emons, A. M., and Ketelaar, T. (2010). The plant exocyst. J. Integr. Plant Biol. 52, 138-146. doi: 10.1111/j.1744-7909.2010.00929.x

Zhang, Z., Henderson, C., and Gurr, S. J. (2004). Blumeria graminis secretes an extracellular catalase during infection of barley: potential role in suppression of host defence. Mol. Plant Pathol. 5, 537-547. doi: 10.1111/j.1364-3703.2004.00251.x

Zhao, Y., and Davis, H. W. (1998). Hydrogen peroxide-induced cytoskeletal rearrangement in cultured pulmonary endothelial cells. J. Cell. Physiol. 174, 370-379. doi: 10.1002/(sici)1097-4652(199803)174:3<370::aid-jcp11>3.0. co;2-d

Zhu, D., Hu, C., Sheng, W., Tan, K. S., Haidekker, M. A., Sun, A. Y., et al. (2009). NAD(P)H oxidase-mediated reactive oxygen species production alters astrocyte membrane molecular order via phospholipase A2. Biochem. J. 421, 201-210. doi: 10.1042/bj20090356

Zhu, D., Tan, K. S., Zhang, X., Sun, A. Y., Sun, G. Y., and Lee, J. C. (2005). Hydrogen peroxide alters membrane and cytoskeleton properties and increases intercellular connections in astrocytes. J. Cell Sci. 118 (Pt 16), 3695-3703. doi: $10.1242 /$ jcs. 02507

Zuo, X., Zhang, J., Zhang, Y., Hsu, S. C., Zhou, D., and Guo, W. (2006). Exo70 interacts with the Arp2/3 complex and regulates cell migration. Nat. Cell Biol. 8, 1383-1388. doi: $10.1038 /$ ncb1505

Conflict of Interest Statement: The author declares that the research was conducted in the absence of any commercial or financial relationships that could be construed as a potential conflict of interest.

Copyright $(02018$ Liang. This is an open-access article distributed under the terms of the Creative Commons Attribution License (CC BY). The use, distribution or reproduction in other forums is permitted, provided the original author(s) and the copyright owner are credited and that the original publication in this journal is cited, in accordance with accepted academic practice. No use, distribution or reproduction is permitted which does not comply with these terms. 